\title{
AGRICULTURA Y BOTÁNICA. LA HERENCIA DE LA ILUSTRACIÓN*
}

por

\author{
J. Luis Maldonado Polo \\ Instituto de Historia, CSIC
}

RESUMEN: La agricultura y la botánica en España, como disciplinas complementarias, estuvieron muy vinculadas desde el último tercio del siglo XVIII y más aún en el primero del siguiente. El alto nivel alcanzado por la botánica en el periodo ilustrado tuvo una cierta continuidad, asociada a la agricultura, en el tránsito del Viejo al Nuevo Régimen y concretamente desde que Casimiro Gómez Ortega viajara a París en los años de 1775 y 1776 aumentó el vinculo con la ciencia francesa y sus representantes, especialmente con Dubamel de Monceau, cuyas directrices trataría de implantar tras su regreso. Posteriormente Claudio Boutelou y el reinado de José I incrementaría esta influencia. En este artículo pretendo abordar, de manera general, el estudio de la agronomía en la crisis del Antiguo Régimen, época en la que se pretendieron instaurar los presupuestos teóricos ilustrados como forma de mejorar la agricultura y sanear la maltrecha economía. Asimismo incidiré en la culminación de la política ilustrada, que en el marco institucional significó todo un despliegue de posibilidades para extender la nueva agricultura a través de la promoción de un sistema pedagógico de formación de especialistas, instruidos en una enseñanza más moderna y actualizada para implantarlo en muchas de las localidades potencialmente agricolas de todo el país.

Palabras Clave: Agricultura. Botánica. Absolutismo. Enseñanza agrícola. Sociedades Económicas.

ABSTRACT: Agriculture and botany were very closely linked from the last third of the eighteenth
century, and even more so in the first third of the following century. The bigh
standards attained by botany during the Enlightenment continued to some extent,
associated with agriculture in the transition from the Old to the New Regime. This
was specifically the case from the time when Casimiro Gomez Ortega travelled to
Paris, enhancing the link with French science and its representatives like Dubamel
de Monceau, whose directives be would try to introduce following bis return to

- Este trabajo se ha realizado en el marco del proyecto: MEC, nº BHA 2003-04414-C03-01. 
Spain. Subsequently, Claudio Boutelou and the reign of Joseph I would increase this influence. The article seeks to deal in general with the study of agronomy in the crisis of the ancien régime, when attempts were made to introduce enlightened theoretical assumptions as a means to improving agriculture and streamlining the depleted economy. I will also emphasise the culmination of enlightenment policy which, in the institutional framework, represented a full deployment of possibilities for extending the new agriculture through a teaching system, with the training of specialists using more modern and up-to-date education, in many of the potentially agricultural localities throughout the country.

KEY WORDS: Botany. Agriculture. Absolutism. Agricultural education. Economics Societies.

\section{INTRODUCCIÓN}

El interés del tema que se trata en el presente trabajo radica sobre todo en la evidencia de la escasez de estudios que aborden el problema globalmente, durante el período de transición entre la Ilustración y los años en que se estableció la agricultura fundamentada en los conocimientos científicos desarrollados en el entorno europeo. A través de estas líneas no se pretende hacer un análisis exhaustivo de la agronomía en la crisis del Antiguo Régimen, sino tan sólo incidir de manera reflexiva en los aspectos relevantes que supuso la culminación de la política ilustrada con todo un despliegue de posibilidades que permitieron extender la nueva agricultura a través de la promoción de un sistema pedagógico, mediante la formación de especialistas en base a una enseñanza más moderna y actualizada. En este sentido me he propuesto acercarme a un problema de gran importancia para la sociedad española en el tránsito del Antiguo al Nuevo Régimen, valorando el alcance que la formación de esos especialistas tuvo en muchas de las localidades potencialmente agrícolas de todo el país.

La aproximación al tema cosiste en una revisión más o menos crítica de la indagación que han realizado otros autores y en la utilización de una documentación impresa, poco conocida, ofreciendo nuevos materiales para la historia de la botánica agrícola, centrándome en la descripción somera de los sistemas productivos dominantes en el período de referencia. Las fuentes empleadas son básicamente artículos de diversas revistas de la época, de gran relevancia para el análisis del estado de la cuestión y documentos e informes complementarios, junto a dos manuscritos depositados en el Jardín Botánico de Madrid, que aportan datos significativos sobre los protagonistas del proceso renovador, sobre sus dificultades para hacerlo posible y las críticas que se suscitaron abiertamente durante el mismo respecto a la política económica y social del régimen absolutista fernandino.

Los resultados que se ofrecen son por tanto parciales, obtenidos como consecuencia de un trabajo de investigación más amplio y aún sin finalizar, por lo que las conclusiones no pueden ser definitivas y tan sólo merecen ser conside-

Hispania, LXV/3, núm. 221 (2005) 1063-1098 
radas como argumentos más o menos críticos de lo que se conoce sobre el tema, a los que se suman elementos descriptivos basados fundamentalmente en nuevos datos e informaciones documentales de primer orden que complementan y ratifican las tesis de la incoherencia legislativa que imposibilitó una auténtica revolución agrícola o agraria según los cánones seguidos por los países de nuestro entorno.

\section{EL ESTADO DE LA AGRICULTURA ENTRE LA ILUSTRACIÓN Y EL ABSOLUTISMO FERNANDINO: LA ENDEBLE REVOLUCIÓN AGRÍCOLA}

La revolución agrícola que se experimentó en Norfolf, Inglaterra, a lo largo del siglo XVIII, penetró en España a través de los estudios de Henri Louis Duhamel de Monceau (1700-1782), lo que posibilitó que nuestros ilustrados fijaran su atención en este importante ramo de la economía nacional en relación con lo que acontecía en el exterior y tratar de poner remedio a las sucesivas crisis agrarias que sufría la península. El espíritu renovador que inspiró al movimiento fisiocrático español, al igual que sus homólogos europeos, cifró sus esperanzas para el progreso y el bienestar de los pueblos en el desarrollo de la agricultura y la indagación en la naturaleza. Para ello nuestros ilustrados más preclaros, bajo la premisa de luz y racionalidad, se propusieron desde los primeros momentos la creación de Academias o Sociedades de Agricultura en Madrid y provincias, aunque su respuesta inicial se tradujo tan sólo en el establecimiento de las Academias de Agricultura de Lérida en 1763 y la de Galicia en 1765. A este programa fundacional inicial se añadieron todo tipo de iniciativas, entre las que por su trascendencia destacó la instauración de las Sociedades Económicas de Amigos del País, cuyos cometidos sobrepasaron ampliamente los aspectos puramente agrarios. Su tarea a lo largo de los años fue de extraordinaria importancia para nuestra maltrecha agricultura, al impulsar, mediante las comisiones creadas al efecto, intensos programas de renovación y fomento agrario, que encontraron a la veź el complemento idóneo en la promoción y fundación de periódicos y revistas que sirvieron para propagar las ideas reformistas y contrarrestar las que se oponía al ansiado desarrollo agrícola.

A grandes rasgos puede decirse que para los ilustrados españoles la desastrosa problemática económica les llevó a basar su ideario filosófico o doctrinal respecto a la agricultura en dos aspectos fundamentales: por un lado el arcaísmo técnico en que se encontraba el campo español que imposibilitaba el aumento de la producción y por otro, de mayor relieve si cabe, la limitada extensión de sus tierras cultivables o de calidad, ya que la mayor parte eran tierras ociosas o de manos muertas, que impedía un mayor dinamismo en el sector y que en el fondo era la fuente de todos los problemas y el lastre de su posible solución.

La casi totalidad de las tierras de secano pertenecían a fundaciones piadosas, capellanías, vínculos y mayorazgos y eran labradas por arrendatarios y jornaleros con bajos salarios. La conducción de las mieses se hacía en muchos ca- 
sos por cargas a lomos de animales, al contar con pocas carretas y otros elementos adecuados, lo que provocaba muchas veces pérdidas substanciales de grano, al margen del perjudicial hábito de siega de espigas muy altas para evitar el arrastre. Las tareas de trilla, saca, limpia y las demás operaciones que realizaban los jornaleros, se hacían a destiempo por decisiones interesadas y arbitrarias de los propietarios, lo que acarreaba pérdidas de tiempo con la consiguiente exposición a bajas temperaturas y disminución de las cosechas. Las tierras en que predominaban los cultivos de secano eran áridas y pedregosas y tenían que labrarse con arados gruesos y casi cilíndricos "pico de gorrión" para vencer la resistencia de los cantos y guijarros ${ }^{1}$.

El marco legal y jurídico que perpetuaba esta ineficaz e impropia distribución era pues la cuestión institucional previa para acometer la regeneración del campo español, de modo que para los fisiócratas españoles, siguiendo los pasos de los europeos, resultaba imprescindible transformar la arcaica estructura agraria sobre la que descansaba la débil agricultura a fin de poder reiniciar el camino con las nuevas técnicas agrícolas.

Tras intentar esta reforma estructural en profundidad y de modo simultáneo se acometería el aspecto tecnico y formativo, grave sin duda, pero de un alcance más accesible e inmediato. Sin embargo y pese a que ambos asuntos fueron el sustento de la práctica reformadora de la Ilustración española, ésta no se mostró unánime en su ideario y sus pensadores más representativos, en su mayoría hombres de Estado, se decantaron de forma más o menos preponderante por una u otra de las dos concepciones. De manera que la ilustración española albergó en su seno dos grandes posturas, germen de la historia económica española y particularmente de la economía agraria hasta prácticamente la actualidad: por una parte los ilustrados que pusieron su énfasis en la mejora agronómica o técnica a base de fomentar la instrucción agraria; y por otra los que aún reconociendo estas deficiencias se empeñaron en denunciar los estorbos políticos, legislativos y hasta morales que impedían el acceso de los agricultores a nuevas tierras de cultivo rentables.

No obstante fue este segundo aspecto, de mayor calado que el primero, el que predominó en las actitudes y acción política de los más afamados agraristas ilustrados españoles. Desde los cargos que desempeñaron en la esfera gubernamental, académica o de posición social, impulsaron la necesidad de reformas jurídicas desamortizadoras en mayorazgos, bienes eclesiásticos, baldíos, algunas propiedades comunales, junto a la imperiosa necesidad de reducir los privilegios territoriales, de las cabañas trashumantes agrupadas en la Mesta y como consecuencia crear un nuevo tipo de propietario agrícola, tras la eliminación de los estorbos jurídicos sobre la libertad de comercio agrarioº

\footnotetext{
1 BOUTELOU, Esteban: «Varias observaciones sobre la Agricultura de Jadraque» en Semanario de Agricultura y Artes (Madrid) T. XXI, No 531 del 5 de marzo de 1807.

2 Para saber determinados datos y cuestiones relacionadas con el agrarismo y su influencia en la sociedad española hemos utilizado las obras generales de: COLMEIRO, Miguel: Biblioteca de econo-
} 
El espíritu del fisiocratismo francés tuvo una enorme importancia dentro del grupo de ilustrados españoles como Jovellanos, Campomanes, Olavide, Cabarrús, etc., para quienes la agricultura representaba la posibilidad de aumentar la riqueza del Estado y mejorar el nivel de vida de sus habitantes. La modernización del país, según estos mismos autores, debía necesariamente pasar por el camino de las reformas de sus caducas y anacrónicas estructuras socio-políticas y la recuperación e incremento del rendimiento agrícola, basado en nuevas formas de trabajo en el agro, pero de un modo riguroso y científico. En 1795, Gaspar Melchor de Jovellanos en su Informe sobre la Ley Agraria ${ }^{3}$ puso en evidencia las carencias y el atraso del sistema productivo agropecuario español, donde la población dedicada a la agricultura era del orden del 70 u $80 \%$ del total, todos ellos labradores y jornaleros. Jovellanos achacaba el estancamiento agrícola español a factores naturales y geográficos por un lado («estorbos físicos») y a factores sociales y culturales por otro («estorbos morales y políticos»). Sobre estos últimos resalta sobremanera la desigual distribución de la tierra en España desde tiempos remotos, en particular como consecuencia de la colonización que tuvo su origen en la Reconquista cristiana; en concreto los grandes cortijos andaluces surgieron como compensación al valor demostrado en batalla con «despojos y propiedades enemigas que se distribuyeron con mano franca entre los conquistadores». De este modo y a medida que se acercaba el final de la contienda, la mayor parte de los terrenos se repartieron en mayorazgos o pasaron al dominio eclesiástico, es decir que quedaron en poder de las órdenes militares, los nobles y el clero, consiguiéndose desde entonces, y en Andalucía particularmente, que desaparecieran «muchas villas y pueblos pequeños que antes estaban repartidos en la extensión de muchos cortijos». De este fenómeno emergió un pequeño número de familias nobles y entidades eclesiásticas como propietarios de grandes latifundios en la mitad sur de la Península, hasta tal punto que fuera de Andalucía no había a comienzos del XIX, «ningún otro pueblo de Europa, que [tuviera] tan extensas labores al cuidado de un sólo colono. Se halla generalmente por esta causa atrasadísimo y decadente el cultivo de los pingües y feracisimos terrenos de estas fértiles provincias; habiendo decaído su antigua y floreciente agricultura» como aconteció desde tiempos de la dominación musulmana, cuyo sistema agrícola fue muy distinto al de después de su derrota ${ }^{4}$.

mistas españoles de los siglos XVI, XVII y XVIII, Madrid, Real Academia de Ciencias Morales y Políticas, 1953; CORREA CALDERÓN, E.: Registro de arbitristas, economistas y reformadores españoles (15001936), Madrid, 1981; GLICK, Thomas: Historia de la agricultura, Valencia, ETSIA, 1980 y el fundamental repertorio de: RAMÍREZ, Braulio Antón: Diccionario de bibliografía agronómica, Madrid, Rivadeneira, 1865.

3 Sobre este importante Informe, pueden consultarse las ediciones: Madrid, Sancha, 1795 ó Madrid, José Lage, 1986.

4 BoutelOU, Esteban: «Observaciones sobre las grandes labores de Andalucía,...» en Semanario de Agricultura y Artes (Madrid) T. XXIII, No 590 (1808) p. 247. 
Ello llevó aparejado la extrema pobreza de la mayoría del campesinado y la desmesurada riqueza y enorme poder de los aristócratas latifundistas y de las comunidades religiosas, cofradías, etc., cuyos bienes eran cultivados en arrendamiento, diezmos, o por modestos agricultores.

Este acontecer se tradujo en que la mayor parte de la población activa agraria en la España del siglo XVIII estaba sometida a la servidumbre feudal. Las familias trabajadoras carecían de la libertad necesaria para decidir sobre los propios recursos que constituían su actividad cotidiana y sus potenciales iniciativas se veían truncadas por este régimen de dominación medieval. Por supuesto no eran propietarios directos de los esenciales medios de vida como era la tierra, al tener que aceptar sin condiciones el sistema impuesto por los ricos propietarios que les obligaban a aceptar mediante arrendamiento pequeños terrenos cultivables o parcelas de escaso valor productivo, en las que tampoco podían disponer de las cosechas o crías, puesto que la mayor parte de ellas, según convenio, tenía obligatoriamente que cederse directamente en especias y en menor medida en forma de renta dineraria a los dueños del dominio. Es decir los arrendatarios, a cambio del usufructo (o dominio útil) debían pagar al propietario, o dueño del dominio directo, una renta, bien en especie, bien en dinero y, con frecuencia, en ambos bienes a la vez.

Por tanto con este proceder, el sistema vigente durante el viejo régimen benefició sin medida al estamento nobiliario, la iglesia católica y la propia corona, propietarios sin límites del territorio potencialmente agrícola y de la cabaña ganadera, mediante el mecanismo del arrendamiento en las condiciones indicadas, que parcial y temporalmente utilizaron los trabajadores del campo; éstos últimos debían reintegrar a sus dueños una parte nada desdeñable de los productos obtenidos mediante este trabajo por cuenta ajena. Para los arrendatarios éstas limitaciones les impedía cultivar con esmero los terrenos, a causa de los desembolsos y el pago en especias convenidos y muy por el contrario los solían dejar infracultivados o en forme de eriales para alimentar ganados.

Además, a lo largo del siglo XVIII y primeros años del XIX las epidemias, como la padecida en Andalucía hacía 1800, hicieron disminuir el número de jornaleros y peonadas por lo que aumentaron los salarios de los jornales en proporción directa al descenso de mano de obra, lo que también llevó aparejado que se registrasen aumentos de valor monetario en tierras y ganados 5 . El aumento del valor de las propiedades lo sufrieron los arrendatarios, ya que se produjo el reajuste al alza del nivel de rentas pagaderas a los dueños del dominio por el uso familiar durante el tiempo convenido. Para agravar aún más la situación, a toda esta problemática socio-económica que determinó el aumento de los precios, habría que agregar la inexistencia o la bajísima calidad en las

$5 \mathrm{Y}$ en un contexto de ausencia de mercado libre de tierras, donde, además el trabajo no era, ni es, más que un valor comerciable, subsistía el individuo desprotegido y sujeto a los cambios de las leyes del mercado, con lo que los precios de los productos subieron en función de su abundancia o escasez.

Hispania, LXV/3, núm. 221 (2005) 1063-1098 
vías de comunicación terrestre, que unida a las grandes distancias y la baja eficiencia de la tracción animal encarecieron aún más los productos y elevaron el precio de la tierra sin remedio ${ }^{6}$. Pero los señores territoriales, como perceptores de las rentas en especie y de derechos señoriales, se vieron igualmente muy favorecidos por este desajustado sistema monetario provocado por el incremento de los precios y el de la renta de la tierra.

A pesar de las medidas parciales adoptadas a finales del siglo XVIII, el régimen señorial se mantuvo aún con vigor a comienzos del siglo XIX en la España del antiguo régimen. Aunque no existen estadísticas precisas respecto al régimen de tenencia de la tierra, no es aventurado pensar que en los inicios del siglo XIX, más de la mitad como mínimo de las tierras cultivadas pertenecían a la Iglesia y a la nobleza, vinculadas la inmensa mayoría a través de los mayorazgos y la amortización eclesiástica ${ }^{7}$.

Además, a causa de falta de población campesina en las grandes extensiones señoriales, los propietarios se dedicaron a la producción de cereales y a la cría ganadera, por su fácil mantenimiento e indispensable consumo en las ciudades populosas, lo que a la postre les resultaba más ventajoso y lucrativo.

Este último factor agravó más la situación. Los privilegios de que disfrutaba el Concejo de la Mesta, al que pertenecían los grandes títulos nobiliarios, impidió el desarrollo de la agricultura, e hizo prevalecer la ganadería, sobre todo lanar, imposibilitando la vida del pequeño propietario que veía destruidos sus sembrados con gran frecuencia por los ganados. Muchas leyes de la época reflejan esta protección a la ganadería a costa de la agricultura.

El cambio de siglo estuvo marcado por el fracaso de la «revolución agrícola» en lo político y en lo económico. El temor a la influencia de la Revolución Francesa entre nuestros ideólogos ilustrados más sobresalientes, con Floridablanca a la cabeza y la ausencia de reformas en profundidad en cuanto a los sistemas de propiedad y tenencia de las tierras, frustraron las esperanzas de recuperación del campo español ${ }^{8}$. Las periódicas crisis de subsistencia que sufría el pueblo no fueron remediadas con las medidas reformistas empleadas y agravaron aún más el panorama ${ }^{9}$, lo que sirvió para que un nuevo enfoque ideológico se terminara imponiendo. Éste giró en torno a la exaltación del interés privado como único motor y destino de toda actividad económica, e incidió en

6 LÓPez Linage, J.: Agricultores, botánicos y manufactureros en el siglo XVIII, Madrid, $\mathrm{M}^{\circ} \mathrm{de}$ Agricultura, 1989.

7 En Cataluña, Valencia, Galicia, Andalucía, Castilla la Nueva y Extremadura, las tierras senoriales comprendían la mayor parte de la superficie total de esas regiones.

8 Puig-Samper, M.A., SOto ARANGO, D. y MiSAS, R.: «La enseñanza de la agricultura en España entre la ilustración y el absolutismo» en: Nacionalismo e Internacionalismo en la Historia de las Ciencias y la Tecnología en América Latina (Cali) (1997) pp. 417-424.

9 Especialmente significativa por su considerable severidad fue la crisis agraria que transcurrió entre 1803 y 1805 , una de las más devastadoras de la historia de España. 
la necesidad de que los agentes económicos-sociales implicados en la misma pudieran competir libremente.

El derecho sin trabas del individuo a disponer de su propiedad como quisiera es el fundamento esencial de una economía liberal y de una sociedad burguesa. El individuo era superior a las corporaciones. Se tratará por tanto de impedir la coacción, bajo cualquier pretexto, de la facultad que todo hombre tenía sobre el derecho de disponer de su propiedad y, por el contrario, se propugnará que todos gozasen y dispusieran a su antojo del fruto de su trabajo, sin estar sujeta su actividad económico-productiva a registros, reseñas, bandos, denuncias, multas y otras molestias que tradicionalmente sufría la agricultura y la ganadería. Por eso se extendió la implantación del derecho a delimitar y acotar la tierra, a venderla o a arrendarla, sin más limitación que la voluntad de las partes contratantes; del mismo modo que se trató de instaurar la opción de poner cercas en los terrenos comunales, lo que suponía un duro golpe a los derechos de paso de la Mesta. Por otro lado se sugería acabar con las trabas que oprimían a los labradores, permitiendo el libre comercio de granos y frutos en todo el reino, sin temor a las carencias de productos para la subsistencia en el propio territorio, aunque buena parte de ellos se desviaran hacia la exportación.

De manera que en este prometedor panorama las ideas liberales, mantenidas en el aspecto económico por Jovellanos especialmente, se apoderaron de muchas inteligencias despejadas que trataron de poner remedio al estado del campo español.

El tránsito del antiguo al nuevo régimen exigía pues transformar el sistema de la propiedad de la tierra, de acuerdo con en el pensamiento de Adam Smith en su obra La Riqueza de las Naciones ${ }^{10}$ que prevenía de la escasa o nula contribución de los grandes propietarios de la tierra para que adelantase y mejorase el rendimiento del agro. Para aumentar la productividad y el número de trabajadores útiles que posibilitaran una mayor eficiencia, la solución debía pasar sin duda por subdividir las grandes propiedades en medianas parcelas de tierra capaces de sustentar a toda una familia. Todo ello en función de una extensión proporcionada, tanto para las necesidades particulares, como a la provisión de fondos económicos suficientes para un sostenimiento productivo nacional equilibrado. Solución parcial no obstante, que hizo proclamar a Claudio Boutelou en 1808 que «la verdadera riqueza territorial se funda en la población laboriosa, útil, activa y aplicada que rinde beneficios al Estado con su trabajo. El fomentar la industria de la población ociosa será siempre un beneficio público, mucho más importante que el que resulta por las conquistas. iQuantos brazos parados pueden conquistarse en España para el cultivo y para las artes!» y más adelante señalaba el prestigioso agrónomo algunas limitaciones a sus tesis «No siempre es ventajoso para los adelantamientos rurales el que pasen a la clase de

10 Edición consultada: Madrid, Alianza, 1994, pp. 808. Estudio preliminar de Carlos Rodríguez Braun.

Hispania, LXV/3, núm. 221 (2005) 1063-1098 
propietarios los individuos pobres, faltos de auxilios y escasos de los fondos correspondientes para establecer un método de cultivo arreglado y competente. Más ventajas resultan para el Estado, y más cómodamente viven estos individuos en los países agricultores, quando perseveran en la clase de braceros. No sucede lo mismo si se subdividen las haciendas en medianas suertes, que labran por su cuenta y en propiedad los sujetos de algunos haberes, que tienen disposición de fondos correspondientes para el cultivo de aquellos terrenos. Es seguramente un golpe político de la mayor importancia el que puedan pasar a propietarios estos hombres laboriosos» ${ }^{11}$.

Ahondando un poco más en la cuestión, en el plano político y legislativo, los liberales españoles fueron herederos de la campaña regalista contra las manos muertas y de los ataques de los economistas a los mayorazgos que tan aceradas críticas provocaron en los ilustrados del XVIII. Desde la llamada desamortización de Godoy se pretendió la adquisición de fondos que contribuyesen a reducir el déficit de la Real Hacienda y ésta fue la línea que los legisladores siguieron desde entonces. Junto a ello en las Cortes de Cádiz, donde se empezó a revelar de forma ostensible ese espíritu individualista, tan típico del modelo liberal, surgió la idea de reducir a propiedad particular el inmenso caudal de los bienes de nuestros municipios y los bienes comunales y de propios, repartiéndolos entre los jornaleros ${ }^{12}$.

Evidentemente el impacto político causado por el Informe de Jovellanos fue grande en el impulso del movimiento desamortizador de las Cortes de Cádiz, quizás más aún en el de las del Trienio Liberal, a pesar de que hasta 1820 fue un texto prácticamente clandestino y su influencia y repercusión decisivas en el de las décadas de 1830 y 1840.

Las tensiones entre los señores y los campesinos se hicieron muy fuertes desde los comienzos de la actividad liberal y las Cortes de Cádiz abrieron el debate político que tuvo su continuidad en las del Trienio Liberal. En este segundo período tuvieron lugar las mismas características reivindicativas y legislativas que se iniciaron en el escenario gaditano y en cuanto a su política agraria, complemento y culminación de las medidas de las de Cádiz, debe verse en la promulgación de leyes tendentes a la reducción de los derechos que se pagaban al rey, a la iglesia o a los propietarios (diezmos), al establecimiento de una

11 Boutelou, Esteban: «Observaciones sobre las grandes labores de Andalucía...» en Semanario de Agricultura y Artes (Madrid) T. XXIII, No 591 (1808) pp. 266 y 267.

12 Reparto que el parlamento propuso en un principio, con el fin de mejorar su explotación, pero que sacaría a la venta más tarde, si bien con la oposición de unos cuantos diputados a quienes parecieron inaceptables estas medidas. Para conocer estos pormenores sobre el proceso redistributivo llevado a efecto por las Cortes de Cádiz puede consultarse la obra de CARRIÓn, Pascual: La reforma agraria, Madrid, Estudios Políticos, Sociales y Económicos, 1931, reeditada en Barcelona, Ariel, 1973. 
contribución que subrogase las rentas provinciales y al comienzo de una real desamortización ${ }^{13}$.

En relación con la reforma de la agricultura y las medidas encaminadas para hacerla posible conviene tener presente que los liberales de Cádiz, con la mejor intención, realizaron la obra desamortizadora en tal forma (en favor de los ricos), que resultó funesta desde el punto de vista social y económico. Quizás influyera en estas medidas, como puso de relieve Esteban Boutelou, la consideración de que el simple arrendamiento en pocos casos se esmera en el mejoramiento ni de la cantidad, ni en la calidad de las operaciones agrícolas de las propiedades ajenas y es por ello por lo que consideraron en un orden secundario el que los propietarios, por el contrario podrían promover la fertilidad de las tierras en un grado superior. De un individualismo extremado, los precursores del liberalismo en España no se preocuparon prioritariamente de una redistribución socialmente aconsejable de la propiedad de la tierra, sino más bien del establecimiento de derechos de propiedad claros y absolutos en el más puro estilo del liberalismo económico de Adam Smith.

En último término y de acuerdo con la opinión de Gonzalo Anes, el fracaso y la frustración resultante de la política agraria de las Cortes de Cádiz, y que nosotros hacemos extensiva también en las del Trienio, bien pudo deberse a una tendencia desmesurada por aplicar rígidamente esquemas legales válidos en países más desarrollados, como Inglaterra o Francia, pero que a la postre fueron contraproducentes en una sociedad agraria muy desigualmente desarrollada como la muestra. Dadas las peculiares circunstancias en que actuaron las Cortes liberales, al no poder legislar en la etapa de paz ni actuar en la totalidad del país para las de Cádiz y en un clima de inestabilidad y de crispación en las del Trienio, las reformas intentadas quedaron sin aplicación concreta o muy parcialmente desarrolladas ${ }^{14}$.

\section{LA NUEVA AGRICULTURA. LA SÍNTESIS AGRONÓMICA}

Hacia la segunda década del siglo XIX el distinguido agrónomo Antonio Sandalio de Arias estipulaba los datos estadísticos de la superficie cultivada y cultivable de España, junto a otros de tipo demográfico, que nos aportan una visión general de la problemática que interesaba a nuestros pioneros sobre agricultura y política agraria. «De las 150.000 leguas cuadradas de superficie, o lo que es lo mismo, de los 216 millones de fanegas de tierra que tiene España,

13 Maldondo Polo, J. Luis: «Ciencia y política. Los botánicos Mariano Lagasca y Simón de Rojas Clemente en las Cortes del Trienio Liberal» en Hispania (Madrid) LXIII/3, n ${ }^{\circ} 15$ (2003) pp. 1031-1056.

14 ANES, Gonzalo: Economía e ilustración, Barcelona, Ariel, 1969. De éste mismo autor puede consultarse: La ley agraria, Madrid, 1995 y de TOMÁS Y VALIENTE, F.: El marco político de la desamortización en España, Barcelona, Ariel, 1977 pp. 12-38.

Hispania, LXV/3, núm. 221 (2005) 1063-1098 
más de 144 millones están en el día en aptitud de poderse poner en labor; pero es muy cierto que en ningún tiempo han pasado de 51 millones las fanegas de tierra que se han llegado a labrar». Lo que significaba un sobrante elevadísimo, teniendo en cuenta que la población en esos años era de unos 10 millones de personas, de los que unos 670.000 eran «brazos útiles para la agricultura y faenas de cultivo». Por tanto de esa relación tan desigual entre terrenos cultivables y número de los agricultores existentes se deduce que correspondían a cada labrador 215 fanegas, porciones enormemente grandes para los medios y útiles disponibles, lo que implicaba que muchas extensiones quedaran como eriales «tanto más cuanto ninguno en la mayor parte de España destina aquella porción que corresponde para prados artificiales, pues en tal caso se aprovecharían un número considerable de tierras de las que hoy se miran abandonadas.» ${ }^{15}$

Ante esta situación el Informe sobre la ley agraria, que como venimos diciendo fue la síntesis de las ideas y reflexiones de toda una generación de agraristas del siglo XVIII y buena parte de los que continuaron en las primeras décadas del XIX, no contemplaba, sin embargo, los aspectos técnicos y la práctica agrícola que la nueva generación de agrónomos acometieron de manera clara, influidos total o parcialmente por las nuevas corrientes europeas. Tal vez con esta visión más técnica que filosófica, se podría conseguir la efímera, tenue y controvertida revolución agraria o agrícola, pero antes de adentrarnos en esta problemática haremos un pequeño inciso para esclarecer estos dos términos ambivalentes que nos permitan centrar con mayor precisión nuestro discurso.

Las expresiones revolución agraria y revolución agrícola, se han empleado indistintamente con frecuencia para identificar un mismo fenómeno histórico en España. El primero, como bien dice Luis Argemí, se utilizó a lo largo del siglo XIX, como sinónimo de revolución industrial y que abarcaba no sólo los cambios producidos en el sector por las nuevas técnicas agronómicas, sino también por la incorporación de cambios estructurales y jurídicos en las formas de propiedad y tenencia de la tierra. Mientras que el de revolución agrícola se basó en la combinación de la práctica empírica, la rotación de cultivos y la mecanización primaria. Es en este sentido el que a nosotros nos interesa en la continuidad de nuestro trabajo y que se corresponde en rigor con un significado más restrictivo que el anterior. Se empleó a finales del siglo XVIII como indicativo de únicamente esas innovaciones técnicas propuestas por los agricultores

15 ARIAS, Antonio Sandalio: «Discurso pronunciado en la apertura del curso público de agricultura del Real jardín botánico de Madrid, el día 6 de Febrero de 1819" en Continuación del Almacén de Frutos Literarios o Semanario de obras inéditas (Madrid) T.VII (1819) pp. 137 y 138. Sobre esta situación del campo y su problemática son de gran utilidad las obras de: COSTA, Joaquín: Colectivismo agrario en España, Madrid, Biblioteca Costa, 1915; CARRIÓN, Pascual: Los latifundios en España, Madrid, Gráficas Reunidas, 1931 y ARTOLA, Miguel y otros: El latifundio, Madrid, M $^{\circ}$ Agricultura. 1978. 
pioneros, que desde los experimentos y las obras sobre agronomía de Jethro Tull en Inglaterra se fueron implantando en toda Europa ${ }^{16}$.

La nueva agricultura que perseguía la intensificación de los cultivos y, basada principalmente en los principios de la nutrición vegetal, se dedicó, gracias a los agrónomos, botánicos y naturalistas europeos a inventar, descubrir y difundir las técnicas y adelantos que marcarían el nacimiento de la llamada revolución agrícola. La nueva agricultura intensiva se centró en la invención de nuevos aperos para la labranza, herramientas y máquinas, en la formulación de teorías e hipótesis sobre la polinización, la inseminación artificial, la introducción de cultivos novedosos, todo ello en base a una sistematización y clasificación de los vegetales con el auxilio de la fisiología vegetal y la genética como ciencias fundamentales. En resumen y con palabras de Argemí, la nueva agricultura se caracterizó por impulsar: el cultivo del trigo en bandas y el uso de la sembradora; la introducción de otras plantas, especialmente las forrajeras, tanto raíces y bulbos como prados artificiales; el uso exhaustivo de labores de tracción a caballo, arados modernizados u otros aperos y el uso de abonos correctores y riegos, o de drenajes en caso de tierras duras ${ }^{17}$.

La mayoría de los autores españoles de segunda fila, pues los pioneros fueron Campomanes, Jovellanos, Sisterres, etc., hicieron más hincapié, a diferencia de éstos, en desarrollar esa segunda postura substancialmente agronómica, muy influenciados sobre todo por la ideología de fisiócratas europeos ${ }^{18}$. Pero, como sus predecesores, se movieron en el ámbito de las Sociedades Económicas de Amigos del País (SSEE) y divulgaron por vía de las llamadas cartillas rústicas, idea original que hay que atribuir a Jovellanos, los métodos de preparación de los terrenos de labor y de las semillas, las formas de coger, escardar, trillar y aventar los granos, de guardar y conservar los frutos y sus formas de transformación y fabricación adecuadas.

A lo largo del primer tercio del siglo XIX, desarrollaron y aplicaron las nuevas técnicas agronómicas descritas por los teóricos anglosajones, e incorporaron ciertos conceptos de François Quesnay, uno de los fundadores de la economía política y de la noción de la «gran agricultura». Tradujeron al castellano a Duhamel, Rozier y al jacobita escocés exiliado en Francia, Henry Patullo; las obras de Tull las conocieron nuestros agrónomos por medio de las ediciones fran-

16 Sobre este fenómeno puede consultarse: Chambers, J.D. y Mingay, G.E.: The Agricultural Revolution, 1750-1850, Bastford, London, 1966.

17 ARgemí, Luis: La revolución agrícola en España, Madrid, Akal, 1994, pp. 27-28. De este mismo autor, Agricultura e ilustración, Madrid, $\mathbf{M}^{\circ}$ Agricultura y Alimentación, 1988 y junto a Ernesto LLuch Agronomía y fisiocracia en España 1750-1823, Valencia, Alfonso V el Magnánimo, 1985.

18 Es obligado señalar la importancia que, a este respecto, tuvo la obra de: CAVANILLES, Antonio José: Observaciones sobre la bistoria natural, geográfica, agricultura, población y frutos del Reino de Valencia, Madrid, Imprenta Real, 1795, lo mismo aunque en un ámbito menos especializado: CAMPOMANES, Conde de: Discurso sobre el fomento de la industria popular, Madrid, Sacha, 1774, o WARD, Bernardo: Proyecto económico, Madrid, Joaquín Ibarra, 1799. 
cesas, e incluyeron muchas de las veces en las traducciones anotaciones e ideas y conceptos propios ${ }^{19}$. Fueron relevantes las traducciones de los Elementos naturales $y$ quimicos de agricultura de Gustavo Adolfo Gyllemborg y los Elementos d'agriculture de Duhamel de Monceau hechas por Casimiro Gómez Ortega en 1794 y 1805 respectivamente y, entre 1797 y 1803, el Curso Complet d'agriculture o Dictionaire universel d'agriculture de Rozier por Juan Álvarez Guerra, en el que colaboraron los hermanos Boutelou en la parte que correspondía a la nomenclatura botánica; Claudio Boutelou fue editor en 1812 de la obra del agrónomo hispano-árabe Abu Sacaría y Sandalio de Arias tradujo unos «Extractos» de Columela que publicó la SEM en 1824; en 1829 se publicó en Barcelona la Química aplicada a la agricultura del conde de Chaptal, cuya edición corrió a cargo de José Rubio. Conviene señalar que el pensamiento de estos precursores, especialmente el de los agrónomos autodidactas como los Boutelou y Arias, se basó en el maridaje entre botánica y agricultura como elemento regenerador del desarrollo agrícola y antecedente fundacional de las futuras Escuelas Técnicas de Agrónomos o Montes de mediados de siglo. Tanto los planteamientos de Claudio Boutelou como los de Sandalio de Arias pueden considerarse de transición entre la vieja y la nueva agricultura, si bien está última ya se encuentra implícita en sus trabajos publicados.

Aparte de las obras fundamentales de éstos y otros autores extranjeros, seleccionaron textos menores y memorias de relativo valor científico, algunas sin aparente novedad en cuanto a muchas de las prácticas que ya eran comunes en la península, pero con la intención de auxiliar a aquellos labradores de regiones más atrasadas donde algunas de esas cuestiones eran importantes o estaban de vigente actualidad. Este fue, por ejemplo, el caso de la difusión de las ventajas que podía aportar en la mejora de la fertilidad de la tierra y con auxilio de la física y la química, la combinación o mezcla de diversas sustancias en la obtención de abono, dependiendo del tipo de suelo y su composición. El conocimiento de los horizontes que forman el suelo cultivable, el humus, su calidad y proporción de las tierras que lo componen, el mantillo, las llamadas camas calientes, etc., fueron elementos fundamentales que estudió Balthasar Sage y que explicó en el Journal de Physique y cuya versión castellana se recogió en algunas páginas de periódicos españoles ${ }^{20}$.

Las labores del campo, como objeto de estudio de la agricultura, eran de la mayor importancia, ya que estas operaciones favorecen la vegetación, reparan la continua degradación de la tierra a medida que se suceden las cosechas e impedían su total esterilización. De los principios teóricos que sustentaban

19 No obstante y pese a este esfuerzo por dar a conocer las obras de los agrónomos más importantes del momento, se echa de menos las del alemán Albrecht Thaer, que representó la culminación teórica de esta doctrina de los agrónomos ilustrados europeos.

20 Véase al respecto la traducción de BOUTELOU, Claudio: «Memoria sobre la tierra vegetal, y sus abonos" en Semanario de Agricultura y Artes (Madrid) T. XXI, Nos.538 y 539 (1807) pp. 249-255 y $265-272$.

Hispania, LXV/3, núm. 221 (2005) 1063-1098 
estas tareas trataron algunos agrónomos europeos, cuyos conceptos dieron lugar a otros tantos sistemas de laboreo o de labores. Desde el sistema de Tull, que considera a las raíces como los únicos órganos encargados del desarrollo vegetal y por tanto de facilitar su extensión con libertad en el suelo, fue la característica principal en la que se basó para fundamentar la funcionalidad de su sistema. Para el agrónomo inglés, los abonos para conservar o aumentar la fertilidad de las tierras resultaban totalmente inútiles y bastaban en su lugar y por si solas las operaciones de laboreo. El sistema de Duhamel, muy coincidente con el de Tull, combinaba estas labores con el uso de los abonos, aunque estaba convencido de las mayores ventajas que suponían las primeras, ahora bien todo ello con la imperiosa necesidad de emplear nuevos instrumentos y herramientas. En contra de estos dos sistemas, el agricultor toscano, Fabroni, adoptó un camino mucho más radical al eliminar casi del todo la intensificación de las labores del campo y potenciar al máximo el empleo del abonado del mismo. Para el abad Rozier, las labores muy repetidas en cortos intervalos resultaban inútiles y hasta perjudiciales, pero creía indispensables otras de aplicación concretas en determinadas fases vegetativas de las plantas en crecimiento; su sistema era bastante sencillo y razonable desde el punto de vista práctico.

La preparación previa de las semillas antes de la germinación fue otra variante en los procedimientos de eficacia agrícola para ciertos agrónomos teóricos, y una constante para algunos de ellos, como Vallemont, que se mostraron igualmente contrarios al uso de abonos y de intensos procesos de labranza.

El combate de las plagas que amenazaban los cultivos se convertía en estos años en uno de los elementos a tener más en cuenta con vistas a su posible control. En España, dos de ellas, por su magnitud y extensión, ocuparon un lugar preponderante en las preocupaciones de nuestros botánicos agrícolas: el tizón del trigo producido por hongos del género Tilletia y la langosta (Dociostaurus maroccanus) fueron objeto de estudio por parte de algunos relevantes autores. Lo importante era librar a las semillas de gérmenes nocivos y en el caso de recursos alimentarios insustituibles como el trigo, uno de los remedios profilacticos que se propusieron consistió en el empleo de la «lechada de cal» para preservarlo del tizón ${ }^{21}$.

Además de divulgar estas soluciones o remedios fito-patológicos, otras técnicas o experiencias concretas sobre diversos hábitos o prácticas agronómicas procedentes tanto de teóricos extranjeros como nacionales, también se pusieron al servicio del público. Este fue el caso por ejemplo de tratar de extender el conocimiento sobre algunas costumbres polémicas acerca del uso de la sal marina como abono, que se ensayaba en varias partes de España con resultados

21 MALdonado Polo, J.Luis y AZCÁRATE, Isabel: «La plaga de la langosta y el tizón del trigo en la España Ilustrada» en Llull (Zaragoza) 15 (29) (1992) pp. 309-330 y GIMBERNAT Y DE GRASSOT, Antonio de: «Sobre las labores y las siembras» en Colección de disertaciones sobre varios puntos agronómicos (Madrid) (1819) pp. 212-221 y 244.

Hispania, LXV/3, núm. 221 (2005) 1063-1098 
más o menos favorables. Sobre la utilización de este recurso para la agricultura habían disertado muchos autores, con opiniones controvertidas y diversas acerca de las bondades de su uso, entre ellos Rozier, Kraft, Alston, Young, Anderson, Parmentier, Duhamel o Erasmus Darwin. Los efectos de la sal común o «muriate de sosa» sobre los vegetales, los terrenos donde puede resultar útil y los métodos de empleo fueron objeto de estudio y experimentación por parte de los hermanos Claudio y Esteban Boutelou en las salinas del suroeste de Andalucía en 1806. Y aunque afirmaban la conveniencia de su utilización con mesura, ya que «quando se emplea con la inteligencia y prudencia que recomiendan los agrónomos más sabios» y esparcida sobre la tierra de cultivo en pequeñas cantidades «excita y promueve la vegetación, pero que usada con exceso la destruye enteramente», los Boutelou, en vista de que sus utilidades resultan siempre relativas, aconsejaban en lugar de la sal el uso de otros abonos abundantes en España y más baratos, como el estiércol común, de mayor actividad fisiológica y eficacia probada ${ }^{22}$.

De igual forma ocurría con la práctica del «majadeo o arraylage» que mejoraba notablemente el abonado de las tierras que usualmente se dejaban en barbecho y que describió en Francia el zoólogo Louis Daubenton, cómo también lo fue la forma de preparar el «alazor ó azafrán de los egipcios», del que en España se conocía tan sólo su cultivo y recolección y que igualmente se había publicado en Francia en los Annales des arts et manufactures ${ }^{23}$.

Otros procedimientos para la obtención de abonos procedentes de experiencias nacionales, como el consistente en el empleo de hornillos para quemar las malas yerbas y arbustos de los campos, que era práctica habitual en Valencia; Cataluña, Aragón y la Mancha, también fueron objeto de polémicas sobre su uso. El sistema de fertilización indicado lo ensayaron en Motril y Baza los hacendados Bernabé Portillo y Pedro Álvarez y hasta cierto punto fueron sus introductores en el campo andaluz. Sin embargo, pocos agrónomos se interesaron por este modo de abonado, ni siquiera el mismo Rozier, gran especialista en la materia, que, no obstante, dedicó algunos comentarios a esta práctica, negando cualquier tipo de utilidad, dado que según él sus cenizas esterilizan el suelo. Ni Duhamel ni Valcárcel por ejemplo hablaron nada en absoluto de ello, mientras Simón de Rojas Clemente, en contra de la opinión de Rozier, alabó las experiencias que en su presencia hicieron los campesinos andaluces y los ensayos de su paisano Miguel Collazo y Castañares en su pueblo de Titaguas ${ }^{24}$.

22. BOUTELOU, Claudio y Estaban: «Reflexiones sobre el uso de la sal marina ó muriate de sosa para abonar tierras» en Semanario de Agricultura y Artes (Madrid) T. XXII. Nos. 548 y 549 (1807) pp. 3-8 y $27-32$.

23 Ambas traducciones son de CLEMENTE, Simón de Rojas: «Extracto de una memoria sobre las ventajas del majadear ó arraylar el ganado...»y «Método con que preparar el alazor de los Egipcios» en Semanario de Agricultura y Artes (Madrid) T. XXII, Nos.553 y 555 (1807) pp. 87-91 y 113-114 resp.

24 CLemente, Simón de Rojas: «Sobre los hormigueros u hornillos»en Semanario de Agricultura y Artes (Madrid), T. XXIII, No 588 (1808) pp. 209-216. 
Labrar menos y cultivar más debería ser el objeto principal del buen agricultor y el lema que inspiraba a estos precursores de la nueva agricultura. La mala calidad de las labores del campo, ejecutadas de manera arbitraria y sin cuidados, dificultaban el progreso de la agricultura española. Durante las faenas de la siega, recolección, trilla, etc., se desperdiciaba energía y recursos financieros a causa del atraso tecnológico y los demás factores coadyuvantes.

Para su progreso era necesario conocer los preceptos teóricos para combatir las malas hierbas, facilitar la extensión de las raíces de las plantas, favorecer la germinación, promover la descomposición adecuada de los abonos animales y conseguir los mejores hábitats para favorecer la acción del agua y los gentes gaseosos y, como no, la lucha contra los parásitos. Para ellos era imprescindible introducir en los campos, en las fábricas y talleres, instrumentos de labor modernos y eficaces, del mismo modo que ocurría en otros países. Procedente de los Annales des arts et manufactures, el botánico Clemente extractó la «Descripción de una máquina muy sencilla para regar», que Lenormad había tratado con algunas observaciones sobre su construcción y que el botánico valenciano perfeccionó y explicó de forma más accesible para el publico interesado ${ }^{25}$.

$\mathrm{Y}$ aunque no fue algo habitual fuera del mundo científico-técnico o académico, la renovación tecnológica del campo contó con algunas iniciativas encomiables, como la que tuvo como protagonista a uno de los vecinos de Jerez de la Frontera, Jacobo Gordon, quien hizo traer de Inglaterra una colección completa de los aperos y otros elementos auxiliares de los más apreciados en ese país, para distribuirlos principalmente por Andalucía. Además Gordon impulsó la viticultura e industria derivada de la vid, fabricando nuevos alambiques para sus bodegas de Jerez, que mejoraron notablemente la destilación y calidad de los aguardientes ${ }^{26}$.

Asimismo aparte de los muy conocidos ilustrados, precursores de las ideas agraristas, otros muchos procedentes ámbitos profesionales diversos, de las letras, la jurisprudencia o la milicia, junto a políticos y funcionarios de la corte, con el paso del tiempo y al margen de su dedicación profesional, se preocuparon por esta problemática e instruyeron y difundieron sus conocimientos por todos los medios posibles, promoviendo los diversos ramos de la agronomía e industrias agrarias. Varios consejeros de Estado por ejemplo, durante los años del sexenio absolutista (1814-1820), estimularon a las corporaciones locales y hacendados más pudientes para que ensayasen, inventasen y adoptasen nuevos elementos y técnicas agropecuarias. Alguno de ellos se empleó a fondo en esta tarea y se ocupó en «aumentar y propagar en España las cabras de Angola», llegando a mantener en sus propias posesiones «un rebaño de más de cien cabezas de dicha especie» y asimismo trató de abrir un pequeño canal de riego

. 25 Semanario de Agricultura y Artes (Madrid), T. XXIII, No 597 (1808) pp. 366-368.

26 BOUTELOU, Esteban: «Observaciones sobre la destilación de los aguardientes en Xerez y Sanlúcar de Barrameda» en Semanario de Agricultura y Artes (Madrid), T. XXIII, No 579 (1808) p. 66. 
que mejorase la situación de muchas de sus haciendas en Extremadura. Este mismo personaje defendió el establecimiento y extensión de prados artificiales, iniciativa que trasladó a sus amigos para que adoptasen el útil sistema de aprovechamiento de las tierras improductivas. Él mismo proporcionó semillas de árboles para proveer las almácigas de los pueblos y aumentar o generar de este modo el patrimonio forestal de los mismos. Otros muchos promocionaron la agricultura en estos años; algunos de ellos conocidos personajes de la nobleza como, Benavente, Infantado, Alagón, Villahermosa, Montsalú, Bardají, Saceda, Hermosilla, Feria, Zubía, Cano Manuel, García de Castro, a los que se pueden añadir otros muchos, entre los que destacaron buena parte de los socios que integraban la Junta de Comercio de Cataluña ${ }^{27}$.

En este mismo sentido, en 1816, el ya nombrado Jacobo Gordon envió a Eusebio Bardají y Azara, embajador español por entonces en Cerdeña y que en esa fecha se encontraba en la localidad conquense de Huete dedicado a la tareas agrícolas en sus propiedades, «una pequeña muestra de arado para la primera labor anual de las viñas». Especificaba además que «sólo la experiencia en la labor por dos años manifiesta su económico principio; el arado para la segunda labor aún no está perfectamente formada, aunque la operación se ha hecho este año tal qual». Prometía que el nuevo se lo enviaría cuando rectificase algunos de sus defectos, junto con uno de sus arados y su correspondiente par de rastrilleras, que por sus muchas ventajas y aplicaciones le serían de gran utilidad ${ }^{28}$.

El mismo Bardají y Azara tuvo una gran participación en el desarrollo y promoción de un arado inventado por el visitador de fábricas de Madrid, Antonio Rejas, ya conocido por su «sembradera» y construido por el carretero Juan de Mata Morales. Tras la primera demostración práctica que se realizó en una fina cercana a Madrid, propiedad del duque de Villa-Hermosa y en presencia de Sandalio de Arias y del marqués de Cerralvo entre otros asistentes, se ratificó la conveniencia de su generalización en España.

$\mathrm{El}$ instrumento de Rejas incorporaba algunas modificaciones a los que ya se utilizaban habitualmente, como la «reja y la vertedera del arado de Small», tal vez el mejor de todos los conocidos entonces, lo que le confería enormes ventajas en las tareas de la labranza como se pudo comprobar en Huete en 1818. El mismo año y en la misma localidad, Bardají fundó o reconvirtió sus propiedades en una peculiar hacienda agrícola, la llamada «heredad de Bardají», en la que reunió, además de muchos instrumentos agrarios, los mejores arados de Italia, Francia e Inglaterra, especialmente el de Small, del que, hizo réplicas de diferentes tamaños para adaptarlos mejor «al par de bueyes que pudiese arar con él comodamente» ${ }^{29}$.

27 ARIAS, A.S.: «Discurso pronunciado en la apertura del curso público de agricultura del Real jardín botánico de Madrid el 21 de Febrero de 1818» en Continuación del almacén de Frutos Literarios o semanario de obras inéditas (Madrid) (1819) pp. 59 y 60.

28 Carta de J. Gordon a Clemente. Xerez, 14 de mayo de 1816. RJB-I, 58,1, 19.

29 "Agricultura" en Crónica Científica y Literaria (Madrid) No114, del 1 de mayo de 1818. 
Por otro lado y profundizando en otros aspectos pedagógicos y divulgativos comentaremos que con el cambio de siglo y especialmente después de la invasión napoleónica, otro grupo de botánicos agrónomos, profesores de los Jardines Botánicos de Madrid y Barcelona fundamentalmente, acometieron el trabajo de síntesis entre las clásicas y modernas concepciones agronómicas partir de algunas publicaciones periódicas y de abreviados manuales de agricultura, que recogían y sugerían las innovaciones que en este campo del conocimiento popularizaron los saberes agronómicos europeos.

Unos años antes de la intervención francesa, como complemento a las traducciones francesas e inglesas y a las aportaciones directas de autores españoles en forma de memorias, cartillas rurales, disertaciones, etc., dos revistas especializadas vieron la luz, encargándose de forma periódica y metódica de este cometido: El Semanario de Agricultura y Artes... en Madrid y las Memorias de Agricultura y Artes en Barcelona, ambas publicadas por la Sociedad Económica Matritense y la Junta de Comercio respectivamente.

El decaimiento de las SSEE en los años finales del siglo XVIII y principios del XIX en cuanto a las reformas estructurales como actividad fundamental desde su origen, dejó paso a una mayor preocupación por la pedagogía y la difusión de los aspectos técnicos o agronómicos, que en el caso de la Matritense fueron la base pormenorizada de sus artículos en el Semanario, todo ello en detrimento de los análisis genuinamente economicistas que habían constituido la esencia doctrinal de los agraristas del Siglo de las Luces. A diferencia de la etapa anterior, las dos publicaciones indicadas carecieron de la incisiva crítica institucional de sus comienzos para el desarrollo de la nueva agricultura, aunque no estuvieron carentes de ciertos reproches pero fuera del ámbito político.

En sus contenidos se analizaban las causas de la prosperidad de algunos pueblos europeos, como el caso de las manufacturas inglesas, e incorporaron reflexiones acerca de los tratados de comercio entre los piases más desarrollados. En ocasiones incluyeron aspectos comparativos entre algunos de ellos que sirvieran de referencia para tratar de imponer derechos arancelarios a ciertos productos industriales importados y estimular por el contrario el fomento de la industria propia, pero siempre con el horizonte de lo acontecido en el extranjero. Sus redactores eran conscientes del gran potencial que representaba le economía agraria española, al estar su naturaleza tan favorecida por el clima, lo que les hacía exclamar que en su suelo «se crian las mejores lanas del mundo; y que a pesar de que tengamos buenas fábricas de paños, con todo nos vemos precisados a vender las sobrantes a los extranjeros que nos las vuelven manufacturadas. Casi lo mismo nos sucede con la seda, el algodón, el cáñamo, el lino, y con otros muchos productos vegetales» ${ }^{30}$.

Las referencias a la agricultura inglesa pueden verse en los escritos y memorias de Antonio Sandalio de Arias, para el que el estado floreciente y prosperidad

30 BouteloU, Claudio: «Introducción». Elementos de Agricultura, Madrid, Martínez Dávila, 1817 , p. III.

Hispania, LXV/3, núm. 221 (2005) 1063-1098 
con la que Inglaterra cuenta se debía «al patriotismo de Mr. Thownshen, el cual habiéndose resuelto pasar el resto de su vida en medio de sus estériles posesiones, tomó tanto empeño en conocer las diversas calidades de tierras y los abonos que pudieran serle más ventajosos, que en breve tiempo excedieron los resultados a las esperanzas que había concebido: su constante observación, su estudio y sus experimentos descubrieron a los ingleses una nueva y abundantisima mina de riqueza general, enseñándoles el medio fácil y sencillo de hacer fructíferos tantos y tan considerables terrenos, como entonces se hallaban abandonados e incultos. Este ejemplo cundió, aunque con alguna lentitud, por toda Inglaterra, y fue la causa de que se introdujesen los prados artificiales, se acrecentase la cría de ganados, se aumentasen los abonos, se multiplicasen las labores, se perfeccionase el cultivo, creciese la industria y se sostuviese el comercio ${ }^{31}$.

Igualmente los redactores de los periódicos agronómicos recogieron datos y noticias para tratar a fondo de analizar la legislación de esos países en relación a la española, calcular su influencia sobre las fábricas e industrias propias y en suma discurrir sobre las causas y efectos de la pujante industria del norte europeo, en especial la inglesa.

Para establecer los límites o extensión adecuados para una agricultura rentable en España y más en concreto en Andalucía, los agraristas españoles recurrieron a sus homólogos británicos como Young o Herrrenschwand, en un intento de contraponer el modelo hispano al de otras latitudes. Este argumento y otros de similar trascendencia fueron ampliamente expuestos, especialmente por Claudio Boutelou en 1808, desde las páginas del Semanario. Mientras que en Andalucía los cortijos superaban las cinco mil fanegas o acres de tierra, en el caso inglés, según Young, no se superaban las 500 o 600, lo que a todas luces suponía un orden de cultivo "generalmente vicioso y perjudicial para los adelantamientos de la agricultura». Era tan excesivamente grande la extensión de estas propiedades de un sólo señor, que le imposibilitaba poder hacer frente por si sólo a las operaciones normales de la labranza «ni menos que tenga a mano capitales bastantes para atender debidamente al cultivo de aquellas inmensas propiedades que han establecido necesariamente el raro sistema de las tres hojas: es decir, que solamente una tercera parte de la tierra produce, la otra se barbecha, y la tercera parte restante se dexa de rastrojo ó de eriazo para dehesa; perjudicándose en consecuencia para el cultivo las dos terceras partes del terreno». Respecto al tipo de arrendamientos de corto plazo, el modelo inglés de nuevo fue el tenido en cuenta por Boutelou, ya que si estos arrendamientos «fuesen más duraderos, se ajustasen por vidas, ó en enfiteusis a estilo inglés» se mejoraría substancialmente el cultivo ${ }^{32}$.

31 ARIAS, A.S.: «Discurso pronunciado en la apertura del curso público de agricultura del Real jardín botánico de Madrid el día 21 de Febrero de 1818» en Continuación del Almacén de Frutos Literarios o Semanario de obras inéditas (Madrid) (1819) p. 61.

32 Boutelou, Claudio: «Observaciones sobre las grandes labores de Andalucía...». en Semanario de Agricultura y Artes (Madrid), T: XXIII, No 590 (1808) pp. 242, 247-248 y 252; Además para 
El Semanario de Agricultura y Artes, se publicó bajo el patrocinio de Godoy e inició su andadura el 5 de enero de 1797 y tuvo en Juan Bautista Virio, Juan Antonio Melón y Domingo García Fernández a sus fundadores. Bajo su dirección el periódico publicó la mayor parte de sus informaciones de manera anónima, con brevedad y con participación del público interesado, mediante cartas que posibilitaban réplicas y contrarréplicas sobre todo tipo de cuestiones agrarias y agropecuarias, un dialogo enriquecedor entre la gente del pueblo y los redactores ${ }^{33}$

En este aspecto, por ejemplo Agustín Pascual, profesor de la Escuela de Veterinaria, intercambio opiniones sobre varios asuntos relativos a esa especialidad, con un curioso aficionado a la veterinaria de residía fuera de Madrid y que mostraba un gran interés en estudiar en la Escuela. Pascual y su interlocutor se refirieron en concreto al uso del salvado en la alimentación animal, y su correspondencia se incluyó en el periódico para que además de solventar los problemas que le sugerían agricultores, hacendados y ganaderos, resultase de utilidad al resto de los interesados en estas cuestiones ${ }^{34}$.

Aparte de estos contenidos y de los compendios, resúmenes y traducciones de repertorios y obras inglesas y francesas, también procedentes del italiano las cuestiones pedagógicas tuvieron su espacio en la prensa española. Como ejemplo señalaremos que se extractaron y tradujeron al castellano los Elementos de Agricultura del profesor Felipe Ré, que se incluyeron en el Semanario, como obra de referencia y de gran utilidad para la enseñanza pública ${ }^{35}$.

La línea editorial del Semanario fue desigual y cambió de forma drástica con el paso del tiempo y con las distintas visiones que aportaron sus responsables, no sólo en cuanto al contenido y la forma de exponer los artículos, sino, y esto es lo principal, hasta los principios ideológicos y la beligerancia política que habían mostrado desde sus inicios sus promotores. Pronto quedó como único redactor

un conocimiento más detallado sobre esta cuestión, en donde alude a uno de los agrónomos más relevantes cono Arthur Young y a la agriculturà inglesa, puede verse el artículo de ZEA, Francisco Antonio: «Extracto de una memoria sobre las causas de la prosperidad de las manufacturas inglesas en contraposición de las francesas", (tomado por el autor de los Annales des Arts et manufactures, tom.XVI) en Semanario de Agricultura y Artes (Madrid), T. XXII. Nos.557 y 558, del 3 y 10 de septiembre de 1807 , pp. 145-148 y 162-168 resp.

33 Este tipo de práctica fue habitual en el periodismo de la época. Véanse al respecto los trabajos de: Hougton, B.: Scientific periodicals: Their historical development, characteristics and control, London, Clive Bingley, 1975; KRONICK, D.A.: A History of scientific and technical periodicals: the origins and development of the scientific and technological press, 1665-1790, Metuchen, N.J., Scarecrow, 1976 y Scientific and technical periodicals of the seventeenth and eighteenth centuries: a guide, Metuchen, N.J., Scarecrow, 1991; CROSLAND, M., In the shadow of Lavoisier: The Annales de Chimie and the establishment of a new science, London, British Society for the History of Science, 1994.

34 Semanario de Agricultura y Artes (Madrid), T. XXI, No 527 del 5 de febrero de 1807. Además sobre la prensa española de ese mismo período se puede consultar: GUINARD, P.J., La presse espagnole de 1737 á 1791 . Formation et signification d'un genere, París, Institut d'Etudes Hispaniques, 1973.

35 BOUTELOU, Claudio: «Introducción». Elementos de Agricultura, Madrid, 1817, p. XVI. 
Melón, hasta 1805, en que fue sustituido por Zea, Clemente y los hermanos Boutelou, todos ellos apoyaron tras $1808 \cdot$ la solución josefina. Tanto Godoy como Melón, muchos años después afianzaron su amistad tras su exilio en París.

En esta segunda etapa, los Boutelou incluyeron, en 1807, en las páginas del Semanario un "Almanak de Hortelanos» en el que explicaban los métodos y las fechas más favorables para ejecutar con acierto las siembras, los trasplantes, las labores y demás operaciones propias de las huertas, así como una razón pormenorizada de las legumbres y hortalizas que deberían cultivarse en cada estación. Toda la información está claramente ordenada por meses a lo largo del año, de manera que con estas instrucciones cualquier hortelano pudiera por si sólo mantener y acrecentar la rentabilidad de su huerta ${ }^{36}$.

El último número del Semanario fue el 417, de 27 de diciembre de 1804, que incluyó una nota en la que se advertía del relevo en la responsabilidad del periódico: «desde el número siguiente corre de cuenta del Real Jardín Botánico de Madrid la publicación de este periódico». Sin embargo en otra "Advertencia» que encabezaba el N443, último del tomo XVII, de junio de 1805 se establecía que «desde el número siguiente, que es el 444 del jueves 4 de julio próximo, comenzarán los profesores del real jardín botánico de Madrid a componer y publicar el Semanario; pues le pertenece desde el primero de enero último esta empresa». Además de resumir las contribuciones que tuvo el periódico hasta esos momentos, «sin costar nada al erario», éstos no se correspondían con las expectativas esperadas en su edición, por lo que "pasando hoy la empresa a mejores manos, que reúnen a sus muchos conocimientos el zelo por el bien de la patria, el amor a la agricultura, y los vivos deseos de corresponder dignamente a la confianza del gobierno, adquirirá cada dia este impreso nuevos derechos al aprecio público; y más con la proporción que tienen de poder comprobar con la práctica los experimentos rurales, cuyas teorías suelen ser tan equívocas si el que las executa no es muy inteligente y meditador».

El Semanario, desde entonces, se convirtió en un periódico oficial, con menor variedad de contenidos y con artículos más extensos y hasta obras completas de sus autores o redactores y estuvo ligado a la Dirección General de Fomento, quizás por eso su tono moderado. Los hermanos Boutelou en el Semanario sentaron la base teórica de la mejora de la agricultura de la primera década del siglo XIX.

Es oportuno señalar que tanto Zea como Claudio Boutelou, junto con otro relevante agrónomo del momento, Agustín Quinto, prestaron apoyo a José I. Este último que desempeñó como comisario de policía, primero en Aragón y luego en Valencia, en la administración josefina, tuvo que exiliarse con el regreso de Fernando VII, mientras que Zea, como hemos dicho, sustituyó a Virio en su cargo. A principios de 1812 el marqués de Almenara, en un intento de controlar las prefecturas andaluzas, parece que nombró a Clemente comisionado en la de Málaga,

36 Semanario de Agricultura y Artes (Madrid), T. XXII, No 552. 
donde precisamente Zea ejercía como Jefe de la Segunda División encargada de la instrucción pública, los establecimientos científicos, jardines botánicos, museos; la industria, la agricultura, etc., todo ello dentro del esquema organizativo de la administración josefina del Ministerio del Interior.

Por su parte las Memorias de Agricultura, que periódicamente publicaba la Junta de Comercio de Barcelona, contaron con la inestimable colaboración del médico gerundense Juan Francisco Bahí (1775-1841), que se interesó por la racionalización de la agricultura mediante el uso eficaz del suelo con un sistema de rotaciones: agricultura alternante y el uso de distintos abonos naturales. La importancia que él atribuyó a la botánica agrícola, sus ideas y proyectos, así como su actividad docente, se reflejaron en la revista, además de incluirse en mayor medida las de botánica médica, su principal dedicación.

\section{LA ENSEÑANZa AgRícola. El PAPEL DE LAS SOCIEDADES ECONÓMICAS DE AMIGOS DEL PAÍS}

En Cataluña, la actividad botánica se centró en la Escuela de Agricultura Teórico-Práctica y Botánica de la Junta de Comercio de Barcelona, dependiente del Jardín Botánico del Real Colegio de Cirugía ${ }^{37}$. La Escuela se creó en 1807 y en ella desempeñó su actividad botánica agrícola Juan Francisco Bahí, pero la ocupación francesa de la ciudad condal entre febrero de 1808 y mayo de 1814 impidió su normal funcionamiento. En realidad éste se inició regularmente a partir de 1815, año en que Bahí pronunció, el 15 de junio, su Oración inaugural en la apertura de la cátedra de botánica que se estableció en Barcelona y en la que dedicó su atención a la agricultura, basada en el conocimiento de las ciencias naturales «con cuya aplicación puedan hacer fértiles las tierras, para que dén abundantes y variadas cosechas, optimos frutos y delicados productos» ${ }^{38}$.

Pero la situación política al final del Trienio Liberal con la caída de la ciudad de Barcelona y del régimen constitucional malogró el funcionamiento de la Escuela y Bahí pasó a estar perseguido en 1823.

Al margen de éste significativo caso catalán, encarnado en la figura de Bahí, la implantación de la enseñanza de la agricultura y su extensión fuera del

\footnotetext{
37 Acerca de la Junta de Comercio pueden verse: IGLESIES I FORT, J., L'obra cultural de la Junta de Comers, Barcelona, Dalmau editor, 1969; BERNAT LÓPEZ, Pascual, «La direcció d'Agricultura de la Real Academia de Ciencies i Arts de Barcelona (1766-1808)» en Nieto GALÁN, Agustí y RocA, Rosell (coords.), La Real Academia de Ciencies $i$ Arts de Barcelona als segles XVIII $i$ XIX. Historia, ciencia i societat, Barcelona, 2000. Sobre la revista publicada: PUIG PLA, Carles, «Las Memorias de Agricultura y Artes (1815-1821). Innovción y difusión de tecnología en la primera industrialización de Cataluña", en Quaderns d'Historia de l'Enginyeria, 2002-2003, vol.5, pp. 27-58.

38 BAHÍ, Juan Francisco: Oración inaugural que en la abertura de la cátedra de Botánica.., que incluye un "Discurso leido por el Señor Barón de Castellét...", Barcelona, Imprenta de Antonio Brusi, 1815, 26pp+VIII
}

Hispania, LXV/3, núm. 221 (2005) 1063-1098 
ámbito madrileño llevada a cabo por el régimen bonapartista, coincidió en el tiempo con las aspiraciones en este asunto de los políticos e intelectuales liberales que se enfrentaban a la intromisión francesa. El 11 de diciembre de $1808 \mathrm{la}$ Gaceta de Madrid publicó un decreto que abolía el régimen señorial, medida que adoptó el gobierno intruso y que es un antecedente inmediato de la decisión de las cortes gaditanas. José I tomó igualmente las primeras disposiciones para reformar la agricultura y complementariamente la enseñanza agrícola en las provincias, ya que hasta entonces ésta se impartía solamente en la Cátedra de Agricultura del Jardín Botánico madrileño, bajo el magisterio de Esteban Boutelou desde 1807. De manera que el 18 de febrero de 1809 el rey decretó la creación de escuelas prácticas de agricultura y economía rural en las provincias, al margen de mejorar y dotar de mayores medios a la de Madrid 39 .

Sorprende un tanto la precocidad de esta política fundacional de centros pedagógicos enfocados a la agronomía en España, cuyos encomiables primeros esfuerzos por su institucionalización han sido, quizás, insuficiente apreciados. Más aún si tenemos en cuenta la presencia de agentes y demás asesores del monarca francés en España, que previsiblemente debieron influir notablemente en este fortalecimiento institucional, sin que al parecer esto hubiera ocurrido con anterioridad y de manera tácita en la propia Francia metropolitana. Basta recordar al respecto que no fue sino hasta la década de los años veinte del siglo XIX en que se abrieron en Francia las primeras escuelas de agronomía, al establecer las agroforestales de Roville, Nancy y Gringnon, mientras que en 1810 se fundó la primera escuela superior de agronomía en Alemania por iniciativa de Thaer y el húngaro Samuel Tessedik dirigirá la segunda en Goergikon. Más adelante en Alemania también se abrirá otra en Hohenheim, tal vez la más importante de Europa por entonces y que desde 1818 dirigió Schwertz ${ }^{40}$.

Adentrándonos más en esta política institucional enfocada a propagar la enseñanza agrícola a toda la península, la decisión tomada por las Cortes el 8 de junio de 1813, mediante el decreto correspondiente, de crear en los pueblos principales o por lo menos en todas las capitales de provincia Escuelas Prácticas de Agricultura no condicionadas a la existencia de jardines botánicos, coincidía

39 Sobre la colaboración de los científicos españoles con el gobierno afrancesado es de obligada consulta la obra de MERCADER RIBA, J., José Bonaparte Rey de España (1808-1813. Estructura del estado español Bonapartista, Madrid, CSIC, 1971. Parece que también el gobierno de José I proyectó la creación de un Museo de Historia Natural, que incluía una cátedra de agricultura y otra de botánica, al que se refiere la obra: ARMillas, J.A. (coord.), La Guerra de la Independencia, Zaragoza, 2001, vol.,I, pp. 301-325.

40 MonTagut CONTreras, E.: "La enseñanza de la agricultura en España en la crisis del Antiguo Régimen" en Torre de los Lujanes, (Madrid) n40 (1999) p. 225. Es oportuno comentar, como expresa este autor, que la primera escuela de agricultura práctica de Horfwyl se fundó en 1804 por Emilio de Fellemberg. Para conocer la situación de la enseñanza de la agricultura en Francia y en otros países, son muy recomendables los estudios publicados por el centro de la educación del INRP como ChARMASSON, Th.; LELORRAIN, A.M.; RIPA, Y., L'einsegnement technique de la Révolution á nos jours. Tome I, de la Révolution a 1926, París, Economica-INRP, 1987. 
con los mismos propósitos de Antonio Sandalio de Arias en su proyecto pedagógico, aunque sin asignar a las SSEE el papel que éste les atribuía. El agrónomo y principal promotor de la enseñanza agrícola española del primer tercio del siglo XIX, vinculaba esta enseñanza con las SSEE desde 1809, fecha en la que prestaba sus servicios al gobierno de José I, mientras que los diputados del período josefino hacían recaer este cometido en la Dirección General de Estudios; de todas formas el decreto no entró en vigor por los acontecimientos políticos subsiguientes ${ }^{41}$.

Estos significativos precedentes y los efectos de la destrucción y agotamiento de los recursos agrícolas que supuso la guerra, sin embargo y paradójicamente, fueron la causa de que pasada la borrasca bélica, la agricultura adelantara en mayor medida que si hubiera gozado del beneficio de la paz y la estabilidad. La emigración voluntaria o forzosa, tanto en la península como en el exterior, con motivo de la persecución política, ocasionó grandes desastres y pese a ser una experiencia triste, resultó ventajosa hasta cierto punto por los efectos que trajo consigo. Permitió a sus protagonistas observar con más interés que nunca las prácticas y costumbres de los piases y territorios de acogida, su industria, su riqueza y lo que es mejor aún su legislación. De manera que el exilio no resultó inútil, sino que reportó ventajas innegables para el progreso de las artes y de las ciencias y muy especialmente para la agricultura.

Una vez terminada la Guerra de la Independencia se retomó el asunto de la enseñanza agrícola y así el 31 de enero y el 27 de septiembre de 1815, dos reales órdenes disponían la creación de seis cátedras de agricultura en las dos Castillas, Andalucía, Extremadura, Galicia y León, con sedes en las ciudades de Valladolid, Ciudad Real, Sevilla, Badajoz, Santiago de Compostela y León, para las que se aportarían 20.000 reales a cada una, de los que 12.000 corresponderían al catedrático y los 8.000 restantes para el terreno destinado a las prácticas y demás emolumentos y gastos de la enseñanza.

Sin embargo los trámites se interrumpieron por la sempiterna burocracia de la Secretaría de Estado y del Consejo de Castilla, por la precariedad del erario público y quizás también en mayor medida por el escaso significado político que el sexenio absolutista concedió a las SSEE. No obstante, sus actividades se reanudaron en 1818 y el 26 de noviembre se dispuso que la SEM convocara y supervisara las oposiciones para proveer las cátedras en las regiones ya mencionadas con algunos cambios de sede: Burgos por Valladolid, Toledo por Ciudad Real y se sustituía Valencia por Santiago ${ }^{42}$. Algunas de ellas, como la de Burgos, nunca se pusieron en marcha y otras tampoco tuvieron mucho éxito. La de Toledo, gracias al prestigio y tenacidad de su catedrático fundador, Francisco

\footnotetext{
41 MISAS JiMÉNEZ, Rolando E.: «Un promotor de la enseñanza agrícola desde la Real Sociedad Económica Matritense: Antonio Sandalio de Arias (1809-1820)» en Asclepio (Madrid) XLVIII (1) (1996) pp. 101-121.

42 Montagut, E.: (1999), op.cit., pp. 229 y 230.

Hispania, LXV/3, núm. 221 (2005) 1063-1098
} 
Martínez Robles, protegido y auxiliado por la Sociedad Económica de la misma ciudad en cuya sede se estableció la escuela, la puso en marcha en 1820 y tuvo un una cierta entidad bajo su dirección hasta 1833 , mayor que muchas de sus homólogas y luego continuó aunque menos activa con su sustituto José Sabas de Rioja como interino hasta 1835. Martínez Robles, aparte de impartir los más modernos conocimientos que existían sobre esta enseñanza, se ocupó «muy particularmente del fomento y crianza de todos aquellos vejetales desconocidos ó poco cultivados en la provincia, cuya introducción y multiplicación pudieran traer ventajas a los labradores» y asimismo iniciar el cultivo de los prados naturales y artificiales, Sobre esta novedosa práctica en Toledo, Martínez Robles comentaba el día de la inauguración de las clases: «acaso no habrá otra provincia, donde sea de mayor interés este ramo de enseñanza. Se ignora casi absolutamente la cultura de los artificiales; y los naturales están abandonados a las yerbas espontáneas» y agregaba otras novedades que se proponía instaurar, dirigiéndose a su auditorio con las siguientes palabras: «Reconociendo lo mucho que se disminuyen vuestras cosechas de aceite a causa de la negra y cruel enfermedad que infesta muchos de vuestros olivares, nos ocuparemos sin intermisión en investigar las causas de mal tan terrible, ensayando todos los remedios imajinables y publicando después los resultados que obtengamos. Será además de nuestro objeto la formación de una biblioteca rural y de un gabinete, donde se contengan con el debido orden los instrumentos rurales más ventajosos y las producciones naturales de la provincia, ya las minerales que tanto abundan, ya también vegetales y animales, sin olvidar los productos artísticos» ${ }^{43}$.

La trascendencia de este tipo de iniciativas tuvo eco en varias SSEE de otras localidades, que independientemente de en las indicadas, en otras también sirvió para fundar o refundar cátedras de agricultura como las de Baena, Valladolid o Palencia. Fuera del ámbito de las SSEE, pero en estrecha conexión con la Matritense, personajes inquietos e interesados por la pedagogía agronómica también colaboraron en este programa fundacional. Éste es el caso del franciscano Miguel Pérez Caballero y Ronquillo al promover el establecimiento de una de estas cátedras en el partido de Llerena, en la provincia de Badajoz. Para ello se valió del decreto de 1815 sobre creación de cátedras de agricultura y en julio y noviembre de ese año Ronquillo solicitó al rey la creación de dicha cátedra, que impartiría él mismo, sin remuneración alguna. El 21 de abril de 1816 se aprobó su establecimiento en los mismos términos que las demás, salvo en lo referente a la dificultad de su financiación. Y aunque las autoridades locales se encargarían de la protección del establecimiento, desde el inicio de sus actividades los propios interesados, los vecinos de varios pueblos de la comarca y los

43 MARTínez RoBLES, Francisco: Discurso inaugural sobre la Necesidad y Utilidad del Estudio de la Agricultura, Toledo, 1820, pp. 34-36. 
alumnos de la escuela, fueron los que aportaron aunque de forma irregular la ayuda económica necesaria para su funcionamiento ${ }^{44}$.

En el plano didáctico, según la real orden de diciembre de 1816, como forma de propagar los conocimientos agronómicos, se recomendaba la adquisición por parte de los ayuntamientos de las Lecciones de Agricultura de Arias y desde ese año, fecha de su primera edición, se convirtieron en el texto oficial para la enseñanza de la agricultura en España.

Por su parte Agustín Quinto publicó en 1818 un Curso de Agricultura Práctica en dos volúmenes, que continuó con un tercero, pero con título distinto y redactado como novela, El barón de Robinski o la moral del labrador. Esta tercera parte, tal vez por la originalidad de su composición tuvo mayor alcance en su divulgación ya que se extractó y publicó en francés. El Curso, por el contrario, fue objeto de polémica en la revista Crónica Científica y Literaria, en donde se evaluó desigualmente su contenido por presentar numerosos errores e importantes carencias sobre los últimos conceptos y novedades de esta ciencia, según la opinión del censor anónimo y ser en cambio un buen tratado de agricultura a juicio del que le replicóts.

Gran parte de las ideas de Sandalio de Arias fueron recogidas y asimiladas por muchos de sus contemporáneos dentro del mundo académico y cultural y tuvieron una influencia decisiva en el desarrollo de su trayectoria científica. Sin embargo la idea de que la educación sería un medio importante para difundir los avances de la los nuevos métodos agrarios pasó a un segundo plano para los políticos y legisladores. Esta formación quedaba supeditada a los cambios políticos previos, que discutieron la cuestión intensamente en las Cortes del Trienio.

Para los liberales era prioritaria la revolución económica a través de una serie de leyes y decretos que perseguían la supresión de la vinculación de la tierra, la desamortización de propios y baldíos, la desamortización eclesiástica y la reducción del diezmo a la mitad; la enseñanza agrícola ayudaría al desarrollo del sector pero de manera secundaria.

De acuerdo con los precedentes de Cádiz y las iniciativas de Sandalio de Arias, en el parlamento se volvió a hacer hincapié en los programas y planes que nunca acababan de asentarse sólidamente. El 5 de junio de 1820 se expuso el proyecto de ley a las Cortes para que se establecieran nuevas escuelas prácticas de agricultura y economía rural. La Comisión de las Cortes encargada de su estudio hizo una serie de objeciones sobre los presupuestos y el resultado de los debates propiciaron que la enseñanza de la agricultura se incluyera en el marco general educativo, según se dispuso en el Reglamento de Instrucción pública, aprobado por decreto de las Cortes el 29 de junio de $1821^{46}$.

\footnotetext{
44 MontagUT, E.: (1999) op.cit., pp. 240-243.

45 «Censura y Respuesta» en Crónica Científica y Literaria, de 16 y 19 de marzo de $1819, \mathrm{~N}^{\text {os }}$. 205 y 206 y 9 de abril de $1819, \mathrm{~N}^{\circ} 212$.

46 Montagut, E.: (1999) op.cit.

Hispania, LXV/3, núm. 221 (2005) 1063-1098
} 
El 15 de febrero de 1821 Juan Francisco Bahí escribió una Memoria exhortando al parlamento sobre la necesidad de promocionar los estudios botánicos y de agricultura. En la parte final de la mima expuso las razones que le habían movido a dirigirse a las Cortes argumentando que «lejos de mi el pensar instruirlas, si sólo indicar unas ideas que hace años abrigaba en mi seno para bien de mi amada patria: justo era que en esta feliz época de la libertad de hablar las pronunciase: lo hago sin el pincel de la elocuencia, pero con la franqueza que me caracteriza, y la sencillez y naturalidad de la cosa rústica de que trato: las Cortes, a cuya sabiduría y tino las sujeto, sabrán guardarlas» ${ }^{47}$

El botánico catalán pretendía que esa formación se convirtiese en requisito obligatorio para poder comenzar los estudios en cualquier facultad universitaria. En especial los curas, jueces, médicos y farmacéuticos deberían haber aprobado previamente un curso de economía rural en escuelas de botánica y agricultura para iniciar sus respectivos estudios. Bahí consideró además que con el auxilio de las ciencias naturales, en especial de la botánica, se conseguiría el rigor imprescindible en el estudio de la agricultura y poder elevarla de este modo al rango de una ciencia.

Las Cortes de 1822 conscientes de la importancia para la economía nacional de la introducción y aclimatación de especies agrícolas y frutícolas de procedencia ultramarina, promovieron este renglón de la agricultura y concedieron a la Sociedad Económica de Cádiz la propiedad de un jardín en el que se hicieron los primeros ensayos con la cochinilla y otros vegetales americanos, además de proporcionar a la misma Sociedad treinta mil reales para el primer año y 15 mil para los años sucesivos para garantizar el éxito de este cometido ${ }^{48}$.

El texto pedagógico de Arias de 1816 al que nos hemos referido, adquirió más importancia a partir de 1819 cuando se implantaron definitivamente las susodichas cátedras de agricultura en varias provincias, además de extenderse su uso y difundirse por otras muchas localidades y más aún durante los años del Trienio Liberal. En este mismo período se publicó la Cartilla Agraria del coronel José Espinosa, escrita en forma de preguntas y respuestas, texto representativo del más puro ideario de Jovellanos, salvo por su tono paternalista y que incorporó todas las novedades técnicas de la revolución agraria ${ }^{49}$.

Estaban Pastor publicó en el exilio londinense, con la ayuda del editor Ackerman, el Catecismo de agricultura (1825), reeditado en 1834 en Madrid, en el que la agronomía y la economía política se funden en un compendio doctrinal,

47 Bahí, Juan Francisco: «De la Trascendencia Publica y Suma utilidad de ganar curso en las escuelas de botánica y agricultura los matriculados en facultad mayor» en Memorias de Agricultura y Artes que se publican de orden de la Junta Nacional de Gobierno del comercio de Cataluña (Barcelona), Tomo XII, meses de enero y mayo de 1821, p. 194.

48 LAGaSCA, Mariano: "Conaturalización de la cochinilla en el mediodia de España»en Ocios de españoles emigrados (Londres) 7 (1827) p. 123.

49 EsPINOSA, José: Cartilla agraria, o sea, la práctica de la agricultura y de la ganadería según los autores más clásicos de estos miembros, Madrid, León Amarita, 1822. 
similar a los de los fisiócratas franceses e ilustrados españoles. Esta imbricación argumental reaparecerá, aunque de manera más tímida, a partir de la segunda mitad del XIX con autores como Alejandro Oliván y F. Caballero y más tarde, en pleno auge del movimiento regeneracionista, con Joaquín Costa y los reformadores agrarios.

Ya hemos comentado que los cambios de la estructura agraria, modificación de las formas de la extensión de cultivo y régimen de propiedad de la tierra, fueron los argumentos sobre el que más insistieron los ilustrados e intelectuales reformistas españoles tras la revolución agrícola que surgió en el norte de Europa, tras los experimentos de Norfolk. La influencia externa en materia educativa, tuvo igualmente como referencia principal el modelo anglosajón. El agrónomo inglés Young que, a través de sus escritos, viajes y ensayos agrícolas, amplió notablemente los horizontes de la agricultura europea, proponía en el plano educativo la fundación de cátedras de agricultura en todas las universidades británicas, en las que se adquiriesen las ideas y conceptos necesarios sobre la economía rural y la instrucción suficiente sobre la práctica agrícola. De este modo se impedirían muchos desaciertos políticos y muchos reglamentos y ordenanzas perjudiciales para la agricultura y el bienestar público, que se promovían y promulgaban por falta de instrucción agraria y de los principios elementales del cultivo. «¿Deberíamos permitir, dice el mismo Young, que se malgasten tal vez infructuosamente infinitos caudales en las universidades para promover lo que se llama educación pública, sin destinar ni una pequeña parte de estos fondos para fomentar la enseñanza agraria?». Idea que repetirían en España Manuel Gil, redactor del Informe sobre la Ley agraria de Jovellanos y muchos de los agraristas españoles de la época ${ }^{50}$.

Las cátedras de agricultura y los centros agrícolas rurales que se pusieron en marcha en Europa rápidamente tras la iniciativa británica, produjeron sus efectos e hicieron adelantar y propagar considerablemente los conocimientos agronómicos. Además una corporación oficial, el Consejo de Agricultura de Londres, ejerció un poderoso influjo en Inglaterra y fue referencia obligada para otros países que como Francia siguieron sus pasos en la creación de instituciones similares, por las ventajas que suponía la intervención del Estado en la planificación de este ramo de la economía, «¿Quien ignora que la Agricultura Inglesa ha llegado a un punto de perfección que asombra, desde que se estableció en Londres un Consejo de Agricultura compuesto de un determinado número de labradores y hacendados inteligentes, que siempre tratan de desterrar abusos y rutinas perjudiciales, y dar a conocer los mejores métodos de cultivo y los más ventajosos y lucrativos para el Estado y para los mismos labradores?. Por su atinada alternativa ó cambio de cosechas han suprimido enteramente el año de barbecho ó descanso de las tierras, cuya práctica, funesta a la Agricultura, les privaba de la mitad de los frutos que podían coger, y cuya reproducción

so BOUTELOU, Claudio: «Introducción». Elementos de Agricultura, Madrid, 1817, p. VII. 
perenne, en vez de desustanciar ó esquilmar el terreno, cada vez lo fertiliza más. Así mismo han dividido el producto de sus tierras en cosechas que sirven para alimentar al hombre, y en las que se emplean para pasto de los ganados, logrando de este modo en todos tiempos una abundancia extraordinaria de granos y de carnes».

De este modo se expresaba Claudio Boutelou el 14 de octubre de 1816 en el discurso inaugural que pronunció en el consulado de Comercio de Alicante, con ocasión de la inauguración de las clases de agricultura y botánica que él mismo impartió en esa ciudad. Para el agrónomo madrileño la agricultura inglesa era el referente básico que necesitaba España al conciliar la iniciativa privada con el proteccionismo estatal, sobre lo que manifestaba que en Inglaterra «a fuerza de la industria de sus habitantes y de la protección del gobierno ha llegado su agricultura al mayor grado de perfección, sirviendo de modelo y de exemplo a las demás naciones, y demostrando que con el trabajo y la constancia se fertilizan hasta las tierras más estériles e infecundas, se superan todas las dificultades y se triunfa del mal clima y de todos los contratiempos» ${ }^{51}$.

Bajo las directrices de la política inglesa en esta materia, la enseñanza agrícola o mejor aún de la botánica agrícola en España debería dirigirse hacia todos los sectores implicados en la agricultura, pero los conocimientos profundos de esta ciencia, si bien todavía con un fuerte contenido empírico, debían adquirirlos tan sólo los profesionales de la disciplina, como ya se puso de relieve en la segunda etapa del Semanario de Agricultura desde que los profesores del Jardín Botánico se hicieron cargo del periódico. Por tanto «los hacendados y poderosos, sin excluir los de la más alta jerarquía, y por último los administradores de las grandes haciendas: unos por otros además de ser los que pueden y deben adquirir tan útiles nociones, están también en disposición de ejecutar los experimentos y ensayos convenientes, introducir nuevas máquinas, adoptar nuevos cultivos, y por su influencia hacer que se generalicen, extiendan y propaguen entre los labradores menos ilustrados». De manera que no se pretendía que el agricultor fuese un botánico consumado "capaz de manejar todas las obras que se han publicado sobre ese ramo, y denominar 3000 plantas distintas», sino que debería conocer, clasificar y describir las especies o variedades más comunes en sus tierras de labor, sin que ignore tampoco los nombres científicos o sistemáticos. También deberán conocer las nociones de lo que es un organismo vegetal, sus partes y estructuras, órganos y las funciones y mecanismos fisiológicos de cada uno y como son los procesos de la germinación, desarrollo, nutrición y reproducción ${ }^{52}$.

s1 BOUTELOU, Claudio: Discurso acerca del origen y progresos de la agricultura,.., Alicante, 1816, pp. 3 y 32.

52 ARIAS, A.S.: Discurso pronunciado en la apertura del curso público de agricultura del Real Jardín Botánico de Madrid, el 8 de febrero de 1817.., Madrid, 1819, pp. 19 y 21. 
La estimación por la agricultura de nobles y sabios en tiempos pasados hizo que ésta gozara durante muchos años de un gran esplendor, pero el abandono de los sencillos sistemas antiguos de labrar y cultivar la tierra que se practicaban sumió a la España moderna en la decadencia y el abatimiento. Durante el XVIII y el XIX los agraristas, conscientes de los verdaderos intereses del país, revalorizaron la profesión del agrónomo como fuente de progreso y conseguir un mayor auge productivo, con una nueva agricultura modernizada como soporte de una reforma agraria en profundidad que posibilitara estas aspiraciones. Procuraron suprimir las trabas y obstáculos que se oponían a su progreso, aboliendo todas las cargas y tributos arbitrarios y perjudiciales al propio Estado y conceder plena libertad a los labradores para que pudiesen cultivar cuantas cosechas fuesen capaces de obtener sin necesidad de sujetarse a los caprichos ajenos, ni de solicitar permisos muchas veces gravosos e innecesarios.

La utilidad de las cátedras de agricultura que se establecieron en Francia, Inglaterra, Italia, Alemania, Suiza, Dinamarca, Suecia, o Rusia, basadas en gran parte en las tesis de los pioneros y teóricos de la revolución agrícola europea, Jethro Tull y Arthur Young en Inglaterra o Duhamel de Monceau en Francia, calaron hondo en nuestros agraristas más afamados, quienes, además de todo cuanto se ha dicho, propagaron su instauración y fundamentación pedagógica a través de las Sociedades Económicas de Amigos del País que ellos mismos fomentaron.

El fisiocratismo impregnó de contenido a las SSEE, en las que se rechazaban las políticas amortizadoras tanto de la tierras como de la Mesta y así lo puso de manifestó Claudio Boutelou en 1811 en el seno de la SEM ${ }^{53}$. La propia Sociedad madrileña hizo extensivos estos planteamientos a las demás SSEE españolas para que las transformaciones agrarias se constituyeran en el eje prioritario de sus preocupaciones y que en el terreno científico o académico, se tradujo en una creciente tendencia por conferir a la botánica agrícola el rango de disciplina independiente.

El fomento de la agricultura en las SSEE se canalizó a través de comisiones o «clases de agricultura», que impulsaron numerosos programas y proyectos agro-pedagógicos. Estas secciones acometieron la tarea de conocer la realidad del agro español en las distintas zonas de influencia donde estaban presentes. Pusieron en marcha experiencias innovadoras, difundieron los avances técnicos mediante memorias, lecturas o premios a los labradores que destacaron en los distintos programas que se pusieron en marcha y alimentaron discusiones $y$

53 El contenido de estos comentarios pueden verse en la memoria titulada «Apuntes sobre varios vicios de la legislación con respecto a la agricultura». Sociedad Económica Matritense (SEM), 205/4. De los contenidos, tanto bibliográficos como de los volúmenes manuscritos de la Sociedad, puede consultarse: MUR RENGIFo, María Pilar: La biblioteca de. la Real Sociedad Económica Matritense de Amigos del País en 1975, Madrid, RSEMAP, 1978 y sobre el funcionamiento y actividad de la misma en el período josefino: Demerson, G.: «La Sociedad Económica Matritense en tiempo de José I» en Boletín de la Real Sociedad Bascongada de Amigos del País, XXV, 1 (1969), pp. 43-64.

Hispania, LXV/3, núm. 221 (2005) 1063-1098 
polémicas sobre los problemas estructurales relativos a la economía política, la propiedad, la Mesta, etc.; igualmente reunieron gran cantidad de obras agronómicas en sus bibliotecas y archivos.

La importancia que Sandalio de Arias tuvo en esta propagación de iniciativas e ideas, en las que el predominio de las cuestiones pedagógicas era fundamental, se puede valorar por la repercusión que nuevamente sus Lecciones de Agricultura tuvieron desde 1816, a raíz de su publicación. Muchos fueron los elogios y agradecimientos que se le hicieron por su obra desde entonces, junto con la favorable acogida que tuvo en las SSEE y fuera de ellas. Le enviaron multitud de cartas de adhesión y alguna, como la procedente de la Sociedad de Córdoba, que le mando uno de sus miembros, Manuel María de Arjona, además se ensalzar su mérito le nombraba socio de la misma en reconocimiento a los servicios prestados. Otros socios como Ramón Zubía, de la de Vitoria, fray Antonio Gonzálbez y Abad de la de Alcoy, incluso de la Sociedad Real y Central de París, a través de su secretario perpetuo, le dirigieron igualmente su apoyo y felicitaciones ${ }^{54}$.

Sin restar importancia al fundamental papel que tuvieron, tanto la SEM como la de Vergara, a las que nos referiremos en otra ocasión, dedicaremos los siguientes comentarios a otras SSEE de ámbito peninsular y ultramarino ${ }^{55}$, que nos relacionan sus actividades con la enseñanza de la agronomía en conexión con el protagonismo que en ellas tuvieron los botánicos agrícolas vinculados al Jardín madrileño, como es el caso particular de la de Sanlúcar de Barrameda para las peninsulares.

La Sociedad Económica de Sanlúcar de Barrameda, creada en $1781^{56}$, se encontraba a principios de siglo, como las del resto de España, en un lamentable estado de decadencia. Muchos de sus fundadores habían fallecido entre otras causas por la terrible epidemia de fiebre amarilla que tantos estragos causó en la provincia de Cádiz, causando en el ánimo de los socios sobrevivientes un estado de preocupación tal que dejaron al cuerpo patriótico sin apenas actividad. Desde finales de 1803 hasta finales de 1805 no obstante, la Sociedad experimento una cierta recuperación, gracias a las medidas que adoptó Godoy, su director y regidor perpetuo, que apoyó su fortalecimiento con el ingreso en sus arcas de más de treinta mil pesos y el anuncio de la futura creación de un patronato. En este intervalo de tiempo, algunos de sus socios más relevantes, como Francisco Terán, Clemente de Perca, Francisco de Paula Rodríguez, el vicario Rafael Colón o Manuel Vázquez, impulsaron desde la Sociedad obras de

54 ARIAS, Antonio Sandalio: Lecciones de Agricultura, Madrid, 1818, $2^{\mathrm{a}}$ ed., pp. VI-VIII.

55 Demerson, P., J., y Aguilar Piñal, F.: Las Sociedades Económicas de Amigos del País en el siglo XVIII, San Sebastián, 1974 y SHAFER, R.J.: The Economic Societies in the Spanish World (1763-1821), Syracuse, 1958.

56 Las demás SSEE gaditanas se establecieron: en 1784 la de Puerto Real, las de Medina Sidonia y Jerez en 1786, dos años después la del Puerto de Santamaría, en 1791 la de Vejer y por último la de Cádiz en 1814 que pervivió durante el absolutismo. 
caridad, sostenimiento de hospicios, creación de escuelas de hilados para las niñas del pueblo, e incentivaron las manufacturas industriales, maquinaria para moler semillas y granos, fabricas de curtidos etc.

La Sociedad también creó una comisión de instrucción pública que formó varios planes y reglamentos científicos y político-económicos para estimular los negocios comerciales; en este ramo Terán, el segundo director de la Sociedad, proporcionó los medios para establecer clases de matemáticas y dibujo y el socio honorario Francisco Amorós ofreció como premios, medallas de oro y plata, a los facultativos sanitarios de Sanlúcar que consiguiesen hacer vacunar contra la viruela a un mayor número de personas; después la vacuna la hizo trasportar «de brazo a brazo» al Puerto de Santa María el militar y también socio de la corporación José Huet. Asimismo la Sociedad formó la consiguiente comisión para desaguar y aprovechar las marismas cercanas, tan perjudiciales por los miasmas que emanaban de sus aguas estancadas y elaboró memorias, planos, etc., para el proyecto de salubridad pública ${ }^{57}$. Amorós, juez consular de la Sociedad, y por acuerdo de la misma, publicó en el Semanario de Agricultura, del que era colaborador, una noticia sobre el cultivo de los navazos y que le sirvió para el discurso que pronunció en la Sociedad el 30 de noviembre de 1803 . La noticia estaba basada fundamentalmente en la información del viajero francés Lasterie y en la que el mismo periódico madrileño incluyó en su tomo $6^{\circ}$ sobre ese tipo de huerto que se forma en ciertas zonas andaluzas al ahondar en los arenales de sus marismas.

Otro de los miembros de la Sociedad gaditana, el coronel Francisco Abadía, puso en marcha varios establecimientos rurales públicos siguiendo las pautas de las últimas doctrinas agronómicas. Empleó presidarios en los cultivos, con la intención de conseguir efectos correctores en las costumbres penitenciarias y dignificar la vida de los penados y puso en práctica ventajosos ensayos agrícolas, plantíos de árboles y vegetales exóticos ${ }^{58}$.

En esta última faceta la Sociedad sanluqueña promocionó la agricultura tropical en concordancia con lo que desde el Jardín Botánico de Madrid se estableció como forma de aclimatar ciertos cultivos procedentes de ultramar. La agricultura se vio reforzada por la puesta en marcha de varios ensayos y experimentos para la propagación de plantas útiles, desconocidas en estas latitudes y mejora de otras autóctonas propias de este clima, disponiéndolas en parcelas, huertos o jardines donde llevar a cabo sus experimentos y ensayos. Para ello siguió los pasos dados por la Sociedad Bascongada en materia de botánica agrí-

\footnotetext{
57 «Breve resumen de los adelantamientos de la Real Sociedad Patriótica de San Lúcar de Barrameda desde el día 5 de Noviembrede 1803 hasta Diciembre de 1805». en Semanario de Agricultura y Artes, (Madrid), T.XIX, No 470, 2 de enero de 1806, pp. 3-9 y reproducido por LARribA, E. y Dufour, G.: El Semanario de Agricultura y Artes dirigido los párrocos (1797-1808), Valladolid, Gráficas Ámbito, 1997, pp. 229-234.

58 BOUTELOU, Esteban: «Observaciones sobre la destilación de los aguardientes en Xerez y Sanlúcar de Barraneda» en Semanario de Agricultura y Artes (Madrid), T. XXIII, N579 (1808) p. 66.
}

Hispania, LXV/3, núm. 221 (2005) 1063-1098 
cola en un huerto anexo al Seminario de Vergara, en el que se llevó a cabo la aclimatación de los cedros de La Habana, ensayos de los nuevos arados y mejoras de las viñas 59 .

En esta misma línea, en algunas de las provincias más meridionales y del levante peninsular tuvieron gran éxito ciertos cultivos exóticos, como chirimoyos, aguacates, etc. En Valencia, la Sociedad Económica, con la eficiencia de Francisco Gil Rodríguez como socio de mérito, prosperó magníficamente el cultivo y elaboración del añil, lo mismo ocurrió en Aranjuez y en uno de los jardines de Málaga fructificaron de modo espléndido el café y el té, se desarrolló muy bien el árbol de Cuba (quiebra-hacha) de madera muy dura y se hicieron plantaciones de cedro americano, caoba y otras especies de maderas preciosas. En esas provincias sureñas y en especial en la de Cádiz, por iniciativa de su Sociedad Económica, con el clérigo Antonio Cabrera a la cabeza, se adaptó y aclimató perfectamente la cochinilla, el valorado insecto americano que produce la grana; la misma Sociedad gaditana extendió su cultivo por los contornos de la ciudad y lo mismo ocurrió en las de Valencia, Murcia, Motril, Málaga y Sevilla ${ }^{60}$.

La Sociedad Económica Aragonesa, precursora en la fundación de la primera cátedra de economía política de España, instauró también en la década de los setenta del siglo XVIII una cátedra de agricultura por iniciativa de Juan Antonio Hernández Pérez de Larrea y del conde de Sástago; éste último, en 1801, puso su jardín botánico particular a disposición de los alumnos de la cátedra para las prácticas. El mismo Larrea, que más adelante se trasladó a Valladolid ${ }^{61}$ como obispo, promovió en la Sociedad Económica de la ciudad del Pisuerga la apertura de otra cátedra de agricultura; ambas cátedras tuvieron cierta importancia por ser las pioneras entre las dieciochescas. En la de Valladolid asistió a sus clases, entre 1803 y 1807, el economista político y jurista de profesión y natural de la misma provincia Luis Nieto que más tarde se destacaría como un relevante agrónomo.

Nieto colaboró en la creación de un jardín botánico en el Prado de la Magdalena de la ciudad castellana, diseñó varios instrumentos par su Sociedad Económica, la misma que le apoyó en 1806 para dotar la cátedra de medios y recursos, a propósito del decreto del año anterior que había incluido a la ciudad entre las que contarían con esa facultad. Lagasca informó favorablemente a la SEM sobre las actitudes de Nieto para que se le concediese la cátedra interinamente y al parecer en 1808 , se le nombró catedrático de agricultura sin rango oficial, aunque poco duró su magisterio por su incorporación a la resistencia contra Napoleón.

La guerra interrumpió las actividades de la cátedra castellana y Nieto, al final de la contienda bélica, se trasladó a la localidad vallisoletana de Adanero

59 Montagut, E.: (1999), op. Cit., pp. 206-207.

60 LAGASCA, M.: (1827), op. cit., pp. 122 y 123.

61 De cuya Sociedad Económica trató: DEMERSON, Jorge: La Real Sociedad Económica de Valladolid (1784-1808): notas para su bistoria, Universidad de Valladolid, 1969.

Hispania, LXV/3, núm. 221 (2005) 1063-1098 
para dedicarse a sus tareas como agricultor, no obstante en 1819 se presentó a las oposiciones convocadas por la SEM para el establecimiento de las seis cátedras, ya mencionadas, en otras tantas provincias, con la mala fortuna de que Valladolid fuese sustituida por Burgos y que Nieto tampoco pudo conseguir en esa ocasión ${ }^{62}$.

En su período de vigencia, la Sociedad Económica vallisoletana promocionó el invento de un trillo que realizó Andrés Herrarte, cuya resonancia fuera de la ciudad hizo que Sandalio de Arias y los redactores de las Memorias de agricultura $y$ artes de Barcelona publicaron la noticia del hallazgo. Después de esta sugerente información, el modelo del instrumento despertó entre los labradores y propietarios agrícolas un deseo de experimentar y cerciorarse de sus utilidades. De modo que en 1817 Narciso Oñate mandó construir uno según la idea original de Herrarte y la Sociedad Económica de Murcia envió a Valladolid una comisión que presenció los resultados del prototipo de Herrarte y en 1818 encargaron varios trillos construidos y mejorados por su mismo inventor. Durante el verano de este año se probaron en Murcia y confirmaron las grandes ventajas que aportaba el invento, por lo que desde ese momento y hasta finales del año siguiente se construyeron más de cien de esos trillos ${ }^{63}$.

Todos los logros y esfuerzos de la Sociedad vallisoletana en estos años no impidieron que en 1819 graves problemas sumieran a la corporación en un lamentable estado de decadencia que la llevaría al borde de su extinción. Las intrigas de los «curiales», es decir de los miembros de los tribunales donde se debatían los contenciosos y litigios contribuyeron a su ruina. Entre ellos destacó, como máximo responsable de las desavenencias, un tal Castor, que con su intervención la pusieron en una situación de gran precariedad y sus escasos socios que aún quedaban, carentes de estímulos e invadidos por el tedio hicieron que la Sociedad estuviese «inducida a un estado algo inferior a la de una cofradía de sastres y zapateros». El 19 de septiembre de ese año, uno de sus miembros más activos, Tomás Araujo, pidió a Lagasca las ayudas que pudiera proporcionar a su condiscípulo Pascual Asensio, mientras durasen las desavenencias, para incorporarse a la recién creada cátedra de agricultura de Burgos, al carecer de recursos la Sociedad Económica vallisoletana por haberse suspendido los ingresos procedentes de las cuotas que aportaban los pueblos para el fomento de la agricultura ${ }^{64}$.

En ultramar ciertos personajes notables de la vida pública, estrechamente relacionados con las SSEE coloniales, realizaron inestimables esfuerzos por acrecentar la tecnificación agrícola en los territorios ultramarinos, aunque sus iniciativas tuvieron la rémora de contar con una férrea oposición de los sectores inmovilistas con intereses contrapuestos. En otras ocasiones los obstáculos pro-

62 MONTAGUT, E.: (1999), op. ct., pp. 224 y 225.

63 Crónica Científica y Literaria. Nos.114 y 246, de 1 de mayo de 1818 y 6 de agosto de 1819.

64 Carta de Tomás Araujo a Lagasca. Valladolid, 19 de septiembre de 1819. RJB-I,56,1,22. 
cedieron de diferentes puntos de vista sobre algunos de los objetivos que algunos de los sujetos de estas corporaciones tenían sobre el modo de enfocar estas cuestiones innovadoras. El 30 de mayo de 1817, se creó el Jardín Botánico de La Habana, por la decidida actuación del Intendente de Hacienda Alejandro Ramírez $^{65}$ y de la Sociedad Patriótica de La Habana. Se inauguró, entre otras razones, con una finalidad agronómica manifiesta que incluía la enseñanza agrícola, pero, sin embargo, su director José Antonio de la Ossa, más dedicado a la botánica sistemática clásica y a la elaboración de una Flora Havanensis, no respondió a esas expectativas. Otros miembros de la Sociedad Económica cubana mostraron su desacuerdo, como el hacendado criollo José María Calvo, que el 12 de diciembre de 1818 presentó a la corporación una Memoria que ponía en duda la exclusividad restrictiva del tipo de enseñanza que se fomentaba e impartía en el Jardín de La Habana y afirmaba por el contrario que era imprescindible establecer en el mismo, según el modelo pedagógico del de $\mathrm{Pa}$ rís, una escuela de agricultura práctica.

Tras el paréntesis del Trienio Liberal, en Cuba cambiaron las tornas y el 10 de abril de 1824 se inauguró la Cátedra de Botánica Agrícola a cargo del coruñés Ramón de la Sagra. A diferencia de Ossa, se ocupó de investigar la nomenclatura y usos de las plantas cubanas, con especial dedicación a sus aplicaciones agro-técnicas. Su éxito no dejó lugar a dudas pues, en 1827, bajo su dirección el Jardín Botánico de La Habana se convirtió en una «hacienda modelo» y más tarde una real orden de 22 de abril de 1829 reforzó aún más esa disciplina, al aprobarse la creación en las inmediaciones de la capital cubana una Institución Agrónoma y Escuela Práctica de Agricultura para los hijos de los labradores en donde se compartiría la investigación con la enseñanza agraria. Sin embargo este segundo aspecto pedagógico quedó enmascarado por la mayor relevancia que adquirieron las investigaciones sobre las plantas agrícolas cubanas, los suelos, abonos, etc., sin duda alguna por la influencia y los intereses económicos de los hacendados y las autoridades coloniales que estimularon por ejemplo los ensayos de cultivo y elaboración del añil que realizó Sagra en colaboración con el químico salmantino José Luis Casaseca y Silván ${ }^{66}$.

En los últimos momentos del reinado de Fernando VII, las SSEE mantuvieron la misma pauta e insistieron en la extensión de la educación agraria por todo el reino, pero poco o nada consiguieron, aunque algo aportaron a pesar de las limitaciones que el monarca les impuso al conferirles tan solo la categoría de «entidades asesoras». En este sentido la real orden de 16 de junio de 1833 les

65 Maldonado Polo, J. Luis: Las Huellas de la Razón, Madrid, 2001, pp. 209-211 y MaldoNADO POlO, J. Luis y PUIG-SAMPER, M.A.: «Ciencia y cultura en la época del Intendente Ramírez en Guatemala, Cuba y Puerto Rico" en Las Antillas en la era de las Luces y la Revolución 1740-1837, Madrid, Siglo XXI, 2005.

66 MISAS, Rolando: «La Real Sociedad Patriótica de La Habana y las investigaciones científicas aplicadas a la agricultura (Esfuerzos de institucionalización, 1793-1864)» en Cuba la perla de las Antillas (Madrid) (1994) pp. 77-80. 
obligaba a que informaran, la decisión final la tomarían otros, sobre el programa de instrucción y difusión de los conocimientos agronómicos que se propuso, como la apertura de una escuela rural en la Corte, la formación de un código rural, el uso de las cartillas rurales en las escuelas primarias o sobre la necesidad de que los eclesiásticos estudiaran como requisito imprescindible para ocupar sus cargos, un año como mínimo de agricultura y economía rural ${ }^{67}$.

Como colofón de cuanto hemos comentado, podemos afirmar que esta última iniciativa y todos los demás decretos, ordenes, planes, proyectos de índole educativa en cuanto a la agricultura resultaron inviables y prácticamente estériles, si antes no se reformaban los aspectos formales, legales y políticos de la estructura agraria, como ya habían puesto de manifiesto los proyectistas y agraristas ilustrados y liberales. El paso de la mentalidad ilustrada a la burguesa exigía una revolución económica como paso previo a la revolución agraria y las medidas desamortizadoras, sin interpretaciones ambiguas y con decisión de auténtico cambio, eran el inicio del proceso, cuestión que las SSEE en el período posterior tampoco pudieron desarrollar.

No obstante los agrónomos ilustrados y liberales del período absolutista, realizaron una meritoria labor científica, técnica y pedagógica, en medio de las tensiones y convulsiones políticas que afectaron negativamente a su quehacer cotidiano. En la mayoría de los casos, estos agrónomos trabajaron en sus gabinetes, en los campos, en las huertas y jardines, sin apenas medios ni materiales ni financieros y bajo la hostilidad de los sectores más reaccionarios del Antiguo Régimen. A pesar de estas dificultades, sus esfuerzos encomiables por mejorar la agricultura española sirvieron para acrecentar la evidencia de la problemática agraria y sentar las bases científico-técnicas e institucionales de la nueva ciencia agronómica y su enseñanza en España. Cuestión esta última que, con el devenir del liberalismo en plena época isabelina, se desarrollaría en todo su esplendor, en especial en lo tocante a la extensión de esta formación académica en todo el marco educativo español.

67 Montagut, E.: (1999), op. cit., pp. 287, 208, 224, 225 y 245.

Hispania, LXV/3, núm. 221 (2005) 1063-1098 